\title{
Simulation study of near-Earth space disturbances: 2. Auroral substorms
}

\author{
Yusuke Ebihara(i)
}

\begin{abstract}
A substorm is a transient phenomenon that lasts for only $1-2 \mathrm{~h}$. One significant manifestation of the substorm is a sudden brightening of the aurora on the nightside. Simultaneously, the auroral electrojets are abruptly intensified in the ionosphere, disturbing the geomagnetic field in the polar region. The near-Earth space environment is highly disturbed, which manifests as an earthward fast flow of plasma, a sudden change in the magnetic field, or a sudden increase in hot plasma. Such disturbances are known to severely affect human society. The ultimate cause of the disturbances is the solar wind, but an explanation of the chain of processes leading from solar wind to the ionosphere is problematic. Here, the evolution of the auroral substorm is reviewed based on the results of a global magnetohydrodynamics (MHD) simulation, called a REProduce Plasma Universe (REPPU) code. The REPPU code is shown to reproduce many aspects of the auroral substorms and to be useful for understanding the primary chain processes from the solar wind to the ionosphere.
\end{abstract}

Keywords: Substorms, Aurora, Computer simulation, Magnetosphere, Ionosphere

\section{Introduction}

A substorm is a transient, complex phenomenon that takes place in the magnetosphere and the ionosphere. It starts with a growth phase, followed by an expansion phase, and a recovery phase. Usually, the substorm lasts for 1-2 $\mathrm{h}$. The terms "polar magnetic substorm" and "auroral substorm" were first suggested by Sydney Chapman (Akasofu, 1968) to represent polar magnetic disturbances and the sudden activation of aurora. Later, Neil M. Brice and Kinsey A. Anderson introduced the term "magnetospheric substorm" to represent magnetospheric disturbances that coincide with both polar magnetic and auroral substorms (Akasofu 1968). The term "substorm" was originally intended to mean an element of a magnetic storm, which is a worldwide magnetic disturbance lasting for a few days. This would mean that a magnetic storm develops when substorms occur frequently. However, some counterexamples are provided (Kamide 1992; McPherron 1997), and the storm-substorm relationship is still an unsolved problem.

One of the most striking and remarkable phenomenon throughout the entirety of the substorm is an explosive

Correspondence: ebihara@rish.kyoto-u.ac.jp

Research Institute for Sustainable Humanosphere, Kyoto University, Gokasho, Uji, Kyoto 611-0011, Japan

(c) The Author(s). 2019 Open Access This article is distributed under the terms of the Creative Commons Attribution 4.0 International License (http://creativecommons.org/licenses/by/4.0/), which permits unrestricted use, distribution, and reproduction in any medium, provided you give appropriate credit to the original author(s) and the source, provide a link to the Creative Commons license, and indicate if changes were made. brightening of aurora followed by expansion (Akasofu 1964; Akasofu et al. 1965), known as auroral breakup. Once the auroral breakup begins, a large amount of energy, exceeding $10^{11} \mathrm{~W}$, is consumed in the polar ionosphere (Ahn et al. 1983; Sun et al. 1985; Kamide et al. 1986; Richmond et al. 1990; Palmroth et al. 2005). The auroral substorm is a subset of the polar substorms, including polar magnetic substorms, ionospheric substorms, $\mathrm{X}$-ray substorms, proton aurora substorms, VLF emission substorms, and micropulsation substorms (Akasofu 1968, references therein). Substorm-associated magnetospheric disturbances have also been identified such as hot plasma injection into the inner magnetosphere (DeForest and McIlwain 1971), high-speed flow in the plasma sheet (Hones and Schindler 1979), and a dipolarization front (Nakamura et al. 2002). Auroral kilometric radiation (Gurnett 1974) is also a notable feature. These disturbances are often used as proxies for the substorm onset, but cannot provide consistent timing for it (Liou et al. 1999). Liou et al. (1999) suggested the use of auroral breakups as a common reference time frame for substorm onset. Therefore, the auroral substorm is of particular focus in this paper.

Global magnetohydrodynamics (MHD) simulation studies have been conducted to understand the evolution of 
substorms. The following is a summary of previously reproduced features and results obtained based on the global MHD simulations: (1) an intensification of auroral electrojets in the ionosphere (Lyon et al. 1998; Wiltberger et al. 2000b; Lopez et al. 2001; Raeder et al. 2001; Tanaka et al. 2010), (2) a midlatitude positive bay of ground magnetic disturbance (Tanaka 2015), (3) Pi2 magnetic pulsation (Tanaka 2015), (4) ground magnetic disturbances from pole to equator including overshielding conditions (Ebihara et al. 2014), (5) the global evolution of auroral patterns (Fedder et al. 1995; Palmroth et al. 2006; Tanaka 2015; Ebihara and Tanaka 2016), (6) localized auroral patterns (Raeder et al. 2012), (7) the evolution of the polar cap boundary (Lopez et al. 2001), (8) an earthward fast flow and associated enhancement of the magnetic fields in the plasma sheet (Hesse and Birn 1994; Tanaka 2000b; Slinker et al. 2001; Raeder et al. 2010; Birn et al. 2011), (9) the formation of a current wedge (Hesse and Birn 1991; Birn et al. 1999; Birn and Hesse 2014), (10) a tailward moving current surge (Ohtani and Raeder 2004), (11) evolution of multiple near-Earth neutral lines (El-Alaoui et al. 2009), (12) energy transfer from solar winds (Papadopoulos et al. 1999; Ebihara and Tanaka 2017), (13) energy conversion in the tail region (Birn and Hesse 2005; Ebihara and Tanaka 2017, and (14) the injection of energetic particles into the inner magnetosphere with the aid of particle simulations, or Fokker-Planck simulations (Birn et al. 1998; Kim et al. 2000; Fok et al. 2006; Ebihara and Tanaka 2013; Nakayama et al. 2017).

In this paper, the simulation results obtained using the REProduce Plasma Universe (REPPU) code (Tanaka 2015) are used to demonstrate recent understanding of the auroral substorm. Detailed information about REPPU is described in the Appendix.

\section{General overview of simulated substorm}

The simulation results overviewed in this paper are obtained using the REPPU code with the following solar wind and IMF parameters (Ebihara and Tanaka 2015a, 2016, 2018) unless otherwise mentioned. Initially, a northward IMF condition was imposed for $2 \mathrm{~h}$ to establish a quasi-steady state magnetosphere: a solar wind density of $5.0 \mathrm{~cm}^{-3}$, a solar wind speed of $372 \mathrm{~km} \mathrm{~s}^{-1}$, the $Y$-component of the interplanetary magnetic field (IMF $B$ ) at $-2.5 \mathrm{nT}$, and the IMF $B_{\mathrm{z}}$ at $4.3 \mathrm{nT}$. IMF $B_{\mathrm{x}}$ was held at 0 throughout the calculation. IMF $B_{\mathrm{z}}$ was changed to $-3.0 \mathrm{nT}$ after $2 \mathrm{~h}$.

Figure 1 shows the $H$-component of magnetic disturbance on the ground at 48 magnetic local times (MLTs) with an interval of $0.5 \mathrm{~h}$ at 70 magnetic latitude (MLAT). The magnetic disturbances were calculated based on the ionospheric Hall current. The upper envelope of the magnetic disturbance can be regarded as Auroral Upper $(A U)$, and the lower as Auroral Lower $(A L)$ indices (Davis and Sugiura 1966). " $T=0$ " is referred to as the moment when the southward IMF reached $X=40$ Re. At $T \sim 20 \mathrm{~min}$, the $A L$ index starts showing a gradual decrease. At $T \sim 70 \mathrm{~min}$, the $A L$ starts decreasing abruptly, which can be regarded as the beginning of the expansion phase of a substorm. These changes are consistent with observation (McPherron 1970). Rapid development of the westward electrojet as manifested by the rapid decrease in $A L$ is also reproduced in the other MHD simulations (Fedder et al. 1995; Pulkkinen et al. 1998; Lyon et al. 1998; Wiltberger et al. 2000a; Lopez et al. 2001; Raeder et al. 2001). The westward electrojet (as seen by $A L$ ) peaks in the post-midnight region, and the eastward electrojet (as seen by $A U$ ) peaks in the post-dusk region. This is consistent with observations (Silsbee and Vestine 1942; Allen and Kroehl 1975; Kamide et al. 1994; Guo et al. 2014).

Figure 2 summarizes the field-aligned current $(\mathrm{FAC})$ in the ionosphere (Ebihara and Tanaka 2018). The simulation

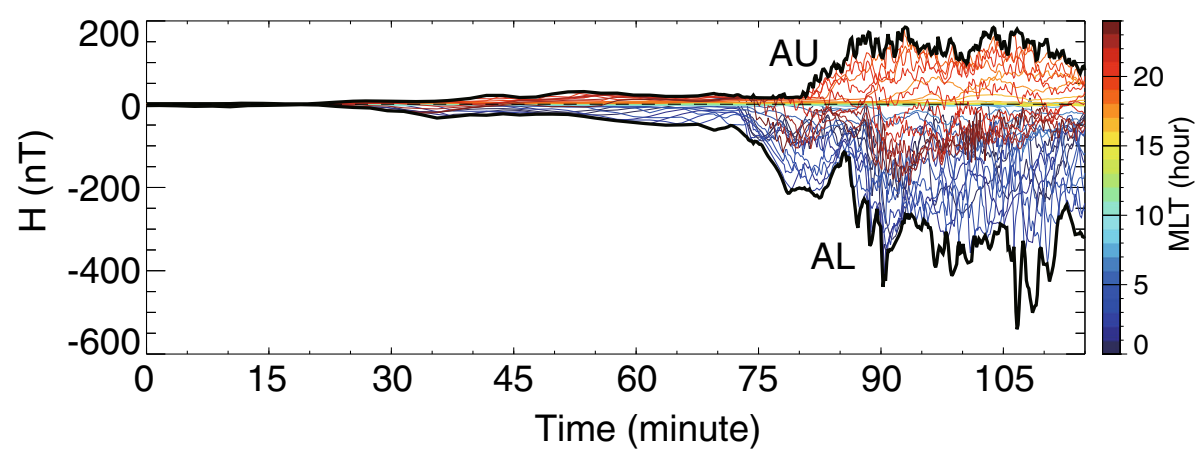

Fig. 1 The H-component of the magnetic disturbance at 70 MLAT and 48 MLTs. The upper and lower envelops are regarded as AU and AL indices, respectively 


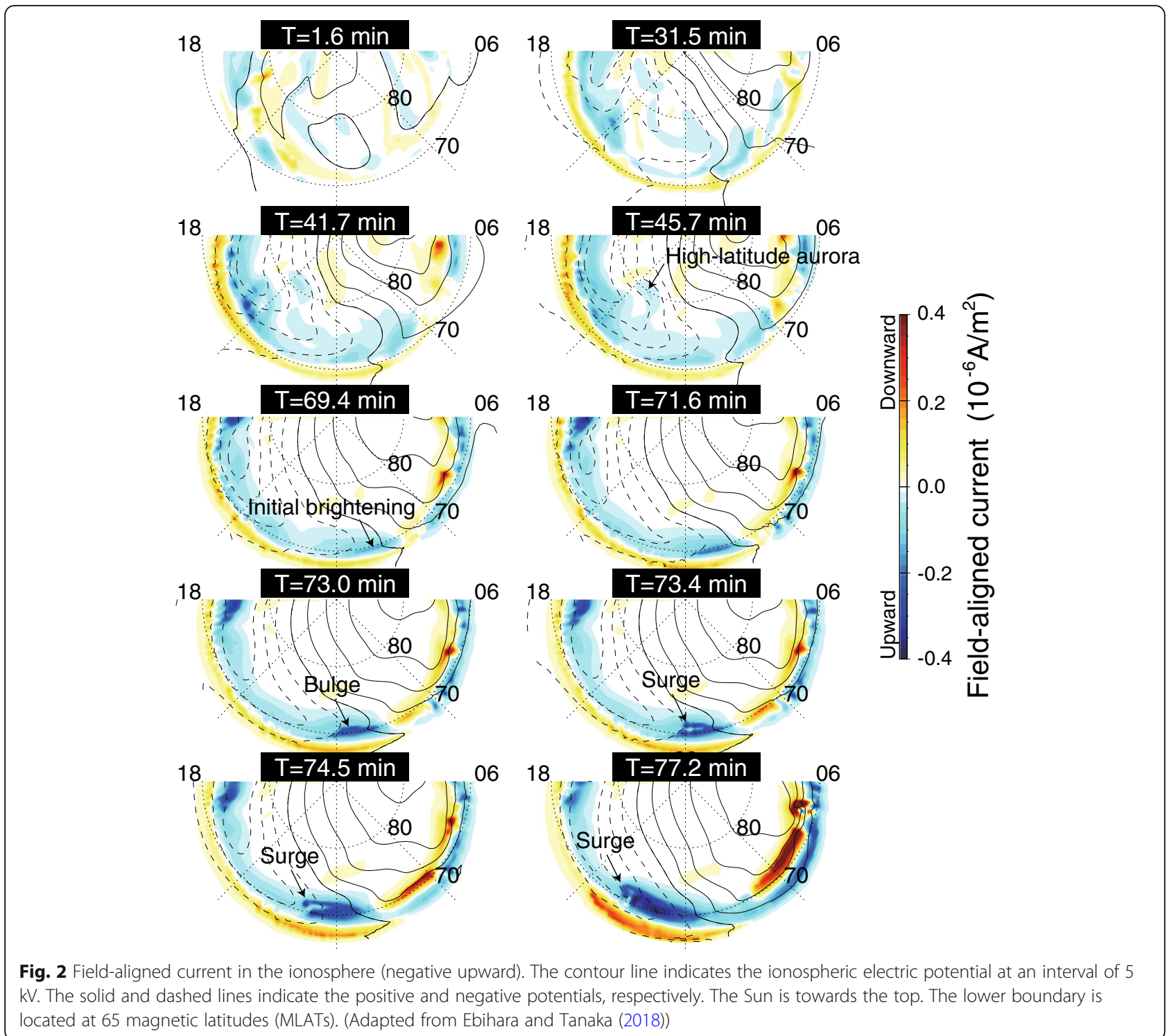

is the same as that used for Fig. 1. In the global MHD simulation, the FAC $J_{||}$is given by

$$
J_{\|}=\frac{1}{\mu_{0}}(\nabla \times \mathbf{B})_{\|}
$$

where $\mu_{0}$ is the magnetic constant. However, a global MHD simulation based on the ideal MHD assumptions cannot deal with the kinetic processes regarding electron precipitation. The emission from excited atoms and molecules in the thermosphere was also not calculated. We used the upward FAC as a proxy of the bright aurora (discrete aurora) because the upward FAC is suitably correlated with the brightness of the discrete aurora (Korth et al. 2014).
1. At $T=1.6 \mathrm{~min}$, the magnetosphere is still exposed to the northward IMF. The distribution of the upward FAC (hereinafter, simply referred to as aurora) is complicated. N-S-aligned structures of aurora are evident at high latitudes, which resemble the sun-aligned arcs observed at high latitudes when the IMF is northward, or close to zero (e.g., Ismail et al. 1977). The structure of the aurora (upward FAC) originates from the structured plasma pressure in the high-latitude magnetosphere as explained later in this paper (Ebihara and Tanaka 2016). Detailed explanation for the sun-aligned arcs is provided in terms of topology of the magnetic field line (Tanaka et al. 2017b).

2. As the IMF turns southward, the two-cell pattern of the ionospheric convection, known as the DP2 
equivalent current system (Nishida 1968), starts developing. The N-S aligned structures move equatorward. For the sake of simplicity, we call them "high-latitude aurorae," which represent structured aurorae inside the main auroral oval, particularly on the nightside. The high-latitude aurorae seem to originate from sun-aligned arcs, and the direction of the high-latitude aurorae can change to the E-W direction, and vice versa. A quiet arc is also evident, which is caused by flow shear in the high-latitude magnetosphere (Tanaka et al. 2017a).

3. At $T \sim 69.4 \mathrm{~min}$, the aurora starts becoming bright in the latitudinally narrow area of the equatorward part of the preexisting aurora. This may be regarded as an initial brightening of the aurora (Akasofu 1964). The brightening occurs at $~ 70$ MLAT in the post-midnight sector for this particular simulation, which is slightly poleward and eastward of the median location of the expansion onset observed by satellite (Liou 2010). Tanaka et al. (2017a) used the same simulation code with different solar wind parameters, showing that the brightening starts at $\sim 68$ MLAT near midnight. Thus, the location of the brightening is probably determined by solar wind parameters and simulation settings, but the determinant factors that control the onset location are still unknown. The expansion onset predominantly takes place in the premidnight sector (Liou 2010). The eastward shift in the location of the expansion onset may be due to the following two factors. One is the skew of the magnetic field line depending on IMF $B_{\mathrm{y}}$. The results of the REPPU code show that the skew is maximized near the equatorial plane near the expansion onset (Saita et al. 2011). Observations show that the location of the expansion onset shifts eastward for negative IMF $B_{\mathrm{y}}$ in the Northern Hemisphere (Liou and Newell 2010). The second factor is the eastward shift of a near-Earth neutral line (NENL), which is described below. The simulated location of the expansion onset is not far from that observed and is within the observational limit as shown in Fig. 3 of Liou (2010). It should be emphasized that the processes behind the substorm are confirmed to be independent of the location of the brightening.

4. After a few minutes, the bright aurora starts expanding poleward, which may be referred to as a bulge (Akasofu 1964).

5. As the bulge develops, an additional auroral structure appears at $T \sim 73.4 \mathrm{~min}$, which propagates westward. This may be referred to as the westward traveling surge (Akasofu 1964). The calculated $A L$

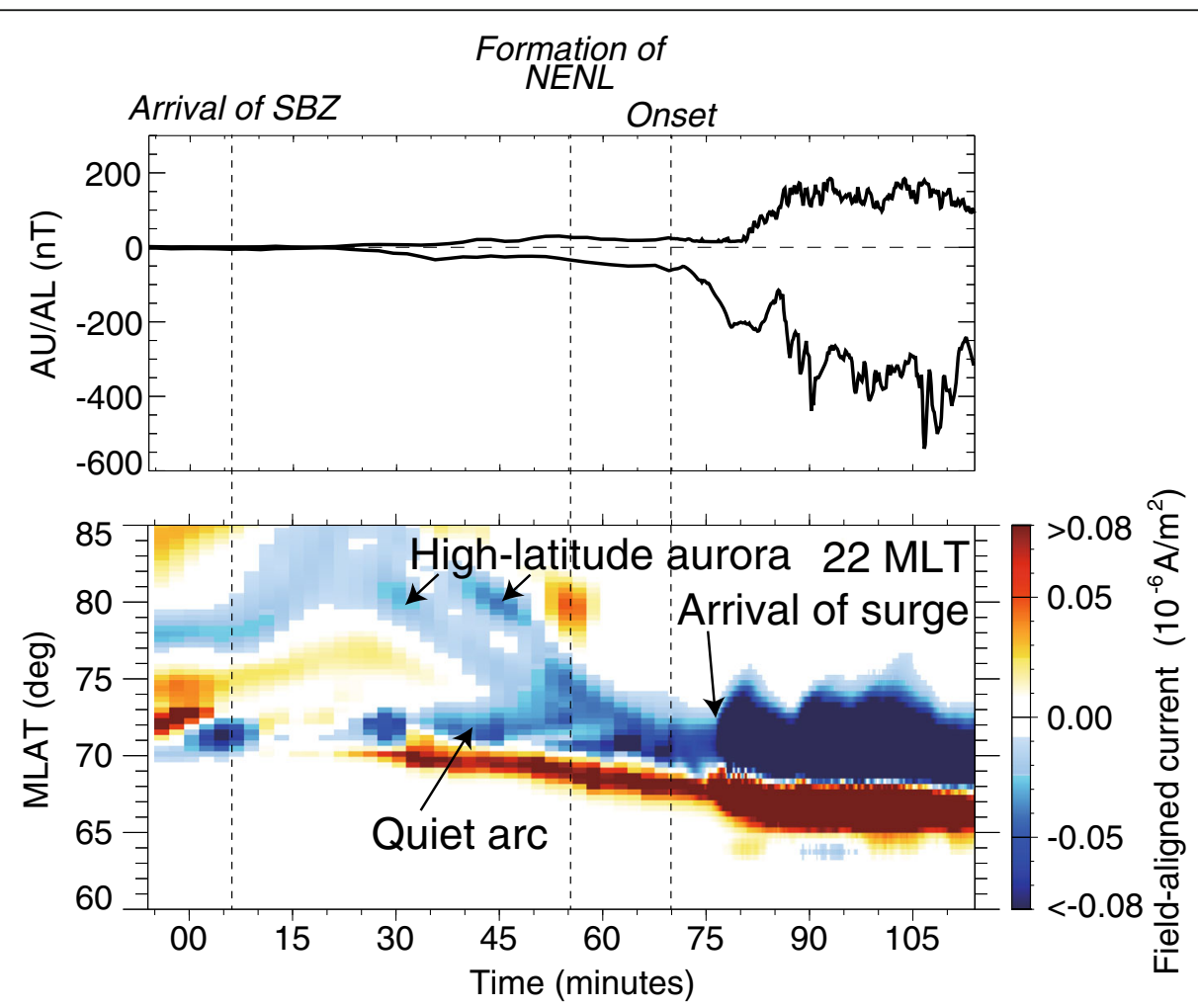

Fig. 3 (Top) AU and AL indices and (bottom) field-aligned currents (negative upward) as a function of MLAT and time. (Adapted from Ebihara and Tanaka 2016) 
index shows an abrupt decrease (as shown in Fig. 1) in association with the development of the bright aurora (Kamide and Akasofu 1975).

Figure 3 shows the FAC as a function of MLAT and time at the meridian at 22 MLT (Ebihara and Tanaka 2016). After the arrival of the southward IMF (SBZ), the auroral structures, regarded as high-latitude aurora, start moving equatorward. After some time, the aurora is intensified at $T \sim 76 \mathrm{~min}$ due to the arrival of the westward traveling surge. In general, the temporal evolution of the aurora is consistent with observations by satellite (e.g., Plate 2 of Brittnacher et al. 1999), although the steady solar wind and IMF conditions are used to drive the REPPU code.

\section{Growth phase}

The term "growth phase" is used to describe a precursor or pre-conditioning stage that occurs before the explosive auroral brightening (McPherron 1970; Akasofu and Snyder 1972). Some auroral structures, such as the quiet arc, move equatorward gradually. Gradual changes in the horizontal component of the magnetic field $(\Delta H)$ are observed in the auroral oval. In the magnetosphere, the strength of the magnetic field in the lobe is gradually enhanced (Fairfield and Ness 1970), and the magnetic field lines are gradually stretched in the magnetotail (Nishida and Fujii 1976). The magnetic energy is stored in the tail region, which is released in the expansion phase (Atkinson 1966; Siscoe and Cummings 1969).

The quiet arc is one of the auroral activities that is often observed during a growth phase (Akasofu 1964; Meng 1976; Lassen et al. 1977; Johnson et al. 1998; Lessard et al. 2007; Haerendel et al. 2012). The quiet arc is also known as a growth phase arc (Haerendel 2010; Lyons et al. 2011; Nishimura et al. 2012), a preexisting arc (Jiang et al. 2012), and a quiet evening arc (Pritchett et al. 2014). On the basis of satellite observation, the thickness of the quiet arcs are estimated to be $\sim 100 \mathrm{~km}$ (Johnson et al. 1998), which may be an upper limit because of the relatively coarse resolution of satellite-borne imaging. Ground-based optical cameras have captured an auroral arc with a thickness of $3.5 \mathrm{~km}$ at $200 \mathrm{~km}$ altitude (Dahlgren et al. 2009). Precipitating electrons with a peak energy of $\sim 1-5 \mathrm{keV}$ are thought to cause the quiet arc, suggesting that the electrons are accelerated by the field-aligned electric field (Meng 1976; Lassen et al. 1977; Haerendel et al. 2012) in the region of the upward field-aligned current (FAC) (Haerendel et al. 2012; Jiang et al. 2012). The upward FAC associated with the quiet arc is thought to originate from an azimuthal gradient in the plasma pressure near midnight (Lyons and Samson 1992; Antonova 1993; Stepanova et al. 2002; Haerendel 2008;
Coroniti and Pritchett 2014). Using the REPPU code, Tanaka (2015) proposed that the quiet arc is generated by the FAC associated with flow shear in the $Y$-direction of the high-latitude magnetosphere. Convective flow from the high-latitude lobe towards the equatorial plane is deflected and divided into the westward and eastward flows off the equator. Another interpretation of the formation of the quiet arc is the precipitation of electrons caused by fieldline curvature scattering (Pulkkinen et al. 1992; Yahnin et al. 1997; Sergeev et al. 2011). The contribution of scattered particles to the formation of the quiet arc should be investigated in the future.

The high-latitude aurorae, which appear within the main auroral oval as shown in Fig. 2, resemble the auroral structures propagating equatorward during the growth phase (Akasofu 1964; Kadokura et al. 2002; Kepko et al. 2009; Nishimura et al. 2010; Mende et al. 2011). The high-latitude aurora is elongated in the N-S or E-W directions. The N-S-aligned high-latitude aurora can switch to the E-W, and vice versa. This is consistent with observational results showing that $34 \%$ of the arcs are east-west (E-W) aligned, 48\% of them are north-south (N-S) aligned, and 19\% switch from N-S to E-W alignments over the course of the equatorward movement (Nishimura et al. 2010). Ebihara and Tanaka (2016) suggested that the high-latitude aurorae are closely associated with the flow vorticity near the complicated structure of the plasma pressure region of the lobe off the equator. Figure 4 shows the evolution of plasma pressure in the $Y-Z$ plane at $X=-7.0 \mathrm{Re}$ and in the $X-Z$ plane at $Y=-1.5 \mathrm{Re}$. At $T=3.7 \mathrm{~min}$, small protuberances of the plasma pressure distribution appear in the lobe as indicated by the arrow in Fig. 4a. During the period from the quiet to the early growth phase $(T=3.7$, 14.6 and $29.6 \mathrm{~min}$ ), protuberances are clearly identified in the $Y-Z$ plane and are shown to evolve away from the equatorial plane. Consequently, the plasma pressure distribution becomes complicated off the equator. Each complicated structure moves away from the equatorial plane and towards the east in the Northern Hemisphere and the west in the Southern Hemisphere. The distribution of the plasma pressure seen in the $Y-Z$ plane is similar to the Rayleigh-Taylor type instability.

Figure 5 is a sketch for the evolution of a protuberance, as the structured plasma pressure distribution (Ebihara and Tanaka 2016). A protuberance of the high-pressure region appears due to some reason (indicated by yellow color in Fig. 5). As the protuberance moves away from the equatorial plane, it induces flow vorticities. Counterclockwise vorticity (viewed in the direction of the field lines) appears at the west of the protuberance, generating downward FAC. Clockwise vorticity appears in the east, generating upward FAC. When these FACs are connected to the ionosphere, the 


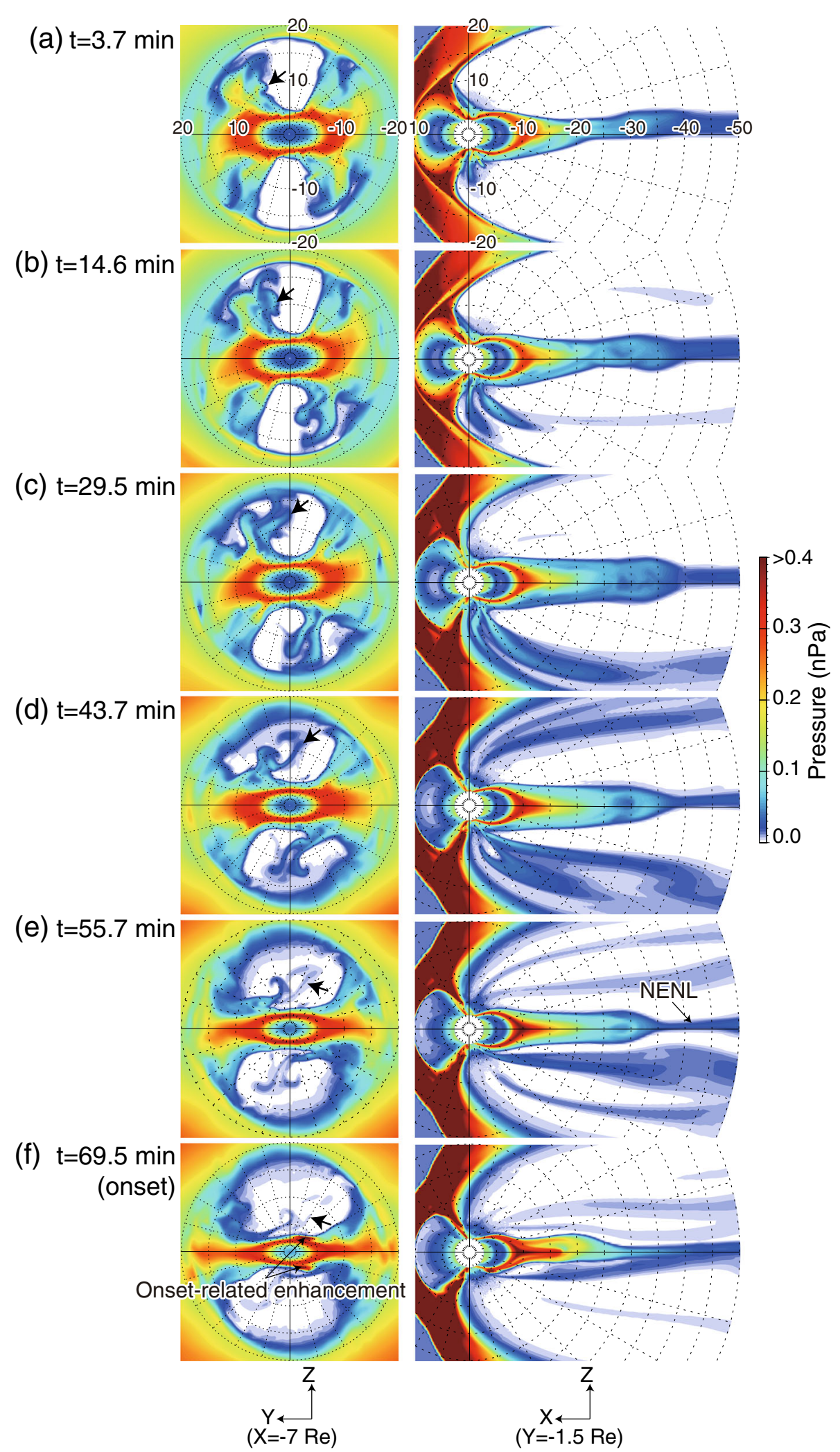

Fig. 4 Plasma pressure in the $Y$-Z plane at $X=-7.0$ Re (left), and in the $X-Z$ plane at $Y=-1.5$ Re (right) at a 3.7, b 14.6, c 29.5, d 43.7, e 55.7, and f $69.5 \mathrm{~min}$. (Adapted from Ebihara and Tanaka 2016) 


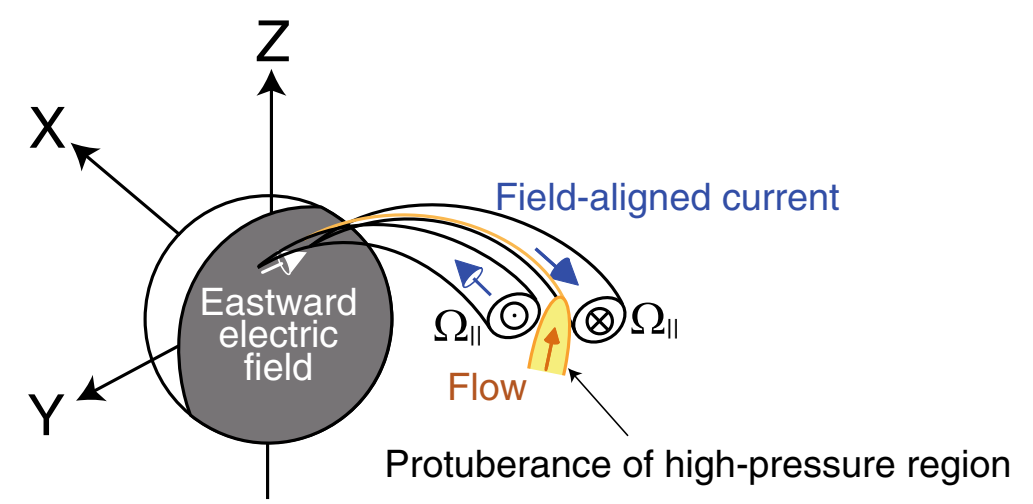

Fig. 5 A possible generation mechanism for the structured distribution of plasma pressure, which is associated with the high-latitude aurorae often observed in the growth phase. (Adapted from Ebihara and Tanaka 2016)

eastward electric field develops to satisfy current continuity in the ionosphere. The eastward electric field propagates into the magnetosphere, causing further development of the protuberance. Because of the non-linear nature, the protuberance (the structure of the high-pressure region) becomes complicated as shown in Fig. 4.

As the IMF turns southward, the magnetospheric convection is enhanced. The structured high-pressure region that appeared off the equator moves towards the equatorial plane due to enhanced convection. Consequently, the high-latitude aurora moves equatorward in the ionosphere $(T=29.5,43.7$, and $55.7 \mathrm{~min})$. The high-latitude aurora is elongated in the N-S direction, or the $\mathrm{E}-\mathrm{W}$ direction, depending on the structure of the high-pressure region. The uncertainty of the direction is consistent with observation (Nishimura et al. 2010).

Figure 6 shows the calculated FACs together with the ionospheric flow (Ebihara and Tanaka 2016). The high-latitude aurorae, elongated in the E-W and N-S directions, resemble observations as shown in Fig. 7 (Nishimura et al. 2010). The high-latitude aurora is located near the westward edge of the equatorward flow channel in the ionosphere. However, a downward FAC is located near the eastward edge of the channel. The equatorward flow channel is caused by the westward electric field arising from the current closure brought by a pair of the localized FACs. These localized FACs are closely associated with the protuberance of the high-pressure region off the equator (Ebihara and Tanaka 2016), and not the plasma sheet, as shown in Fig. 8. One may speculate that the equatorward flow channel is a projection of the earthward flow channel in the plasma sheet and that a pair of the FACs are connected to both sides of the earthward flow channel as illustrated by Sergeev et al. (2000). The simulation result shows that most of the high-latitude aurorae are located in open magnetic field lines as shown in Fig. 8. The white lines in Fig. 8 indicate the magnetic field line extending from the high-latitude aurorae. The magnetic field lines extending from aurorae 1 and 2 are open, whereas the magnetic field line extending from aurora 3 is closed. This means that some of these lines cannot be mapped to the plasma sheet.

The existence of the high-pressure region in the lobe is not confirmed. One possibility is the highly structured ions observed by the Cluster satellite in the lobe region (Shi et al. 2013). These are observed in the northward IMF, with typical energies in the kiloelectron volt range. Shi et al. (2013) explained the ions in terms of the entry of solar wind ions into the high-latitude magnetosphere. However, there is a possibility that the structured ions are responsible for the generation of the high-latitude aurora (Ebihara and Tanaka, 2016). In the global MHD simulation, the structured high-pressure region develops in the northward IMF. If the IMF remained northward over a long time period, the high-latitude magnetosphere would become filled with the high-pressure region as observed by (Zhang et al. 2009). This will be investigated in the near future in terms of the evolution of the high-latitude aurora and the structure of the magnetosphere.

\section{Onset of the expansion phase}

One of the longitudinally elongated auroral arcs, usually the equatorward arc, starts showing a sudden brightening followed by a rapid poleward motion (Akasofu 1964). This is called an auroral breakup. The trigger process leading to auroral breakup is a controversial issue. Observations show that the NENL is closely associated with substorms (Hones et al. 1973; Nishida and Nagayama 1973). It is natural to consider that intense FACs appear in the vicinity of the NENL and initiate the auroral brightening (Baker et al. 1993; Treumann et al. 2006). If this is the case, auroral breakups will start near the poleward boundary of the auroral oval because this is thought to be the open-closed boundary of the magnetic field line. However, observations show that auroral breakups start near the equatorward boundary of the 

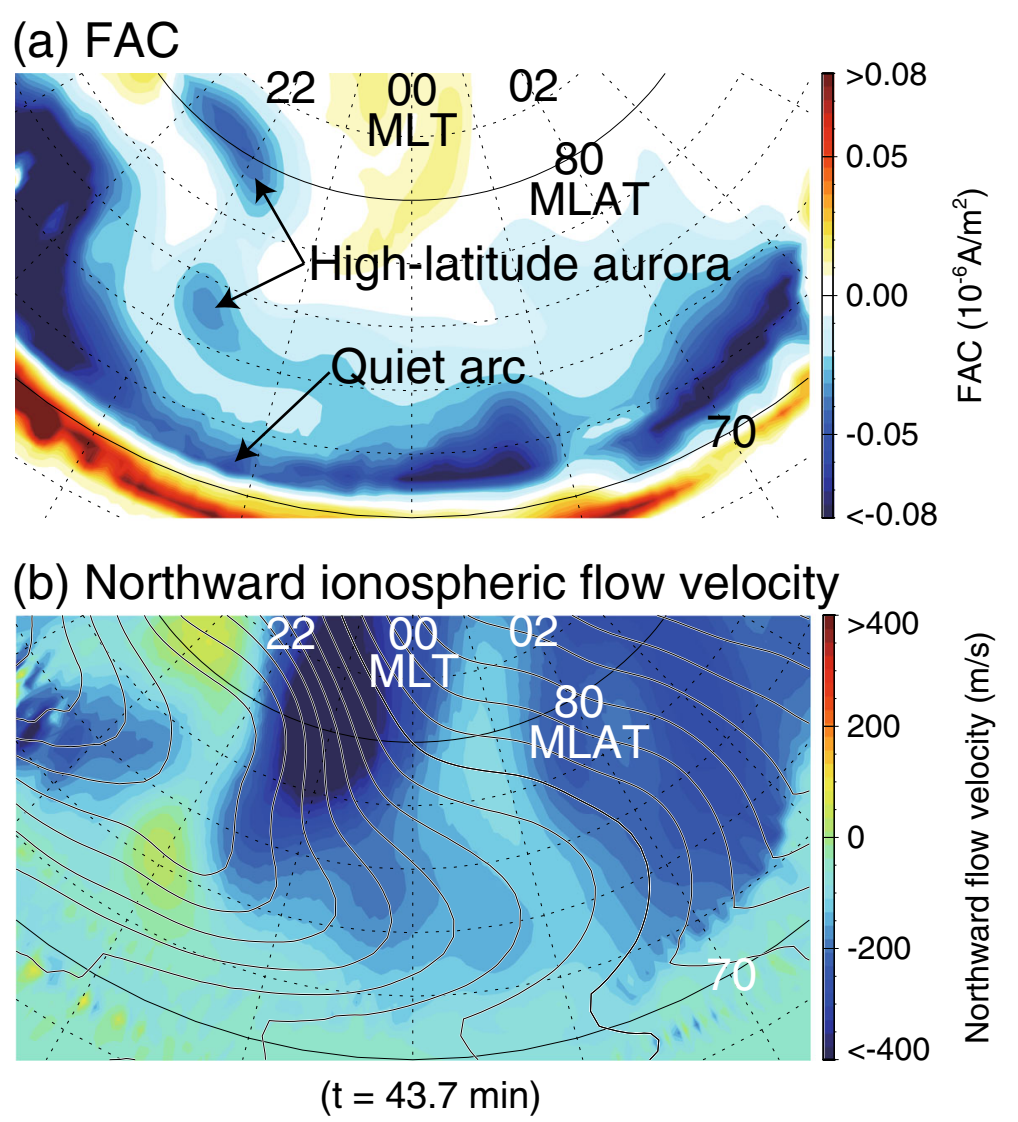

Fig. 6 a Simulated high-latitude aurora and $\mathbf{b}$ northward ionospheric flow velocity during the growth phase (at $T=43.7$ min). The contour line indicates the ionospheric electric potential at an interval of $2 \mathrm{kV}$. (Adapted from Ebihara and Tanaka 2016)

auroral oval (Lui and Burrows 1978; Elphinstone et al. 1991). To solve this problem, a current disruption model has been suggested (Lui 1996). Current disruption is thought to occur in the near-Earth plasma sheet at a radial distance of $\sim 8$ Re and is supported by observations that the magnetic field oscillates in large-amplitude wavelengths, breaking down the frozen-in condition (Takahashi et al. 1987; Lui 2011). Ballooning mode instability is one of the plausible mechanisms leading to the current disruption (Roux et al. 1991; Cheng and Lui 1998; Liu et al. 2012). Once the current disruption occurs, the current wedge $(\mathrm{CW})$ appears as a diversion of the cross-tail current (Lui 1996). Considering earthward flow in the plasma sheet (Hones 1979), one can reasonably regard the formation of the NENL as a trigger of the auroral breakups starting near the equatorward boundary of the auroral oval. Examples include the intrusion of low entropy plasma (Chen and Wolf 1993), inertial current associated with flow braking (Haerendel 1992; Shiokawa et al. 1997), and flow vorticity (Birn and Hesse 1991; Birn et al. 2004b; Keiling et al. 2009). Both the NENL and current disruption models can explain auroral breakups starting near the equatorward boundary.
Many research efforts aimed at understanding the whole process from trigger to auroral evolution have been conducted. However, it was difficult to construct a synthesis model without contradictions due to the limited number of observations. Here, the capability of the MHD model in reproducing the auroral substorm expansion is briefly overviewed. First of all, it should be noted that the MHD model cannot deal with the kinetic processes involved by the current disruption (Lui et al. 1990; Cheng and Lui 1998). Despite this limitation, the MHD model has successively reproduced many aspects of substorm expansion (Tanaka, 2015). In the MHD model, the substorm expansion is triggered by the formation of the NENL. Figure 9 shows an example of the $X$-component of the plasma flow velocity perpendicular to the magnetic field in the equatorial plane at $T=55.7 \mathrm{~min}$. The simulation settings are the same as those used for Figs. 1, 2, 3, 4, and 6. The NENL is identified at $\sim 40 \mathrm{Re}$ downtail. The NENL appears due to an increase in the anomalous resistivity that is a function of the local magnetic field and the current density (Tanaka et al. 2010). For this particular simulation, the location of the NENL is tailward of that typically observed (20-30 Re downtail) 

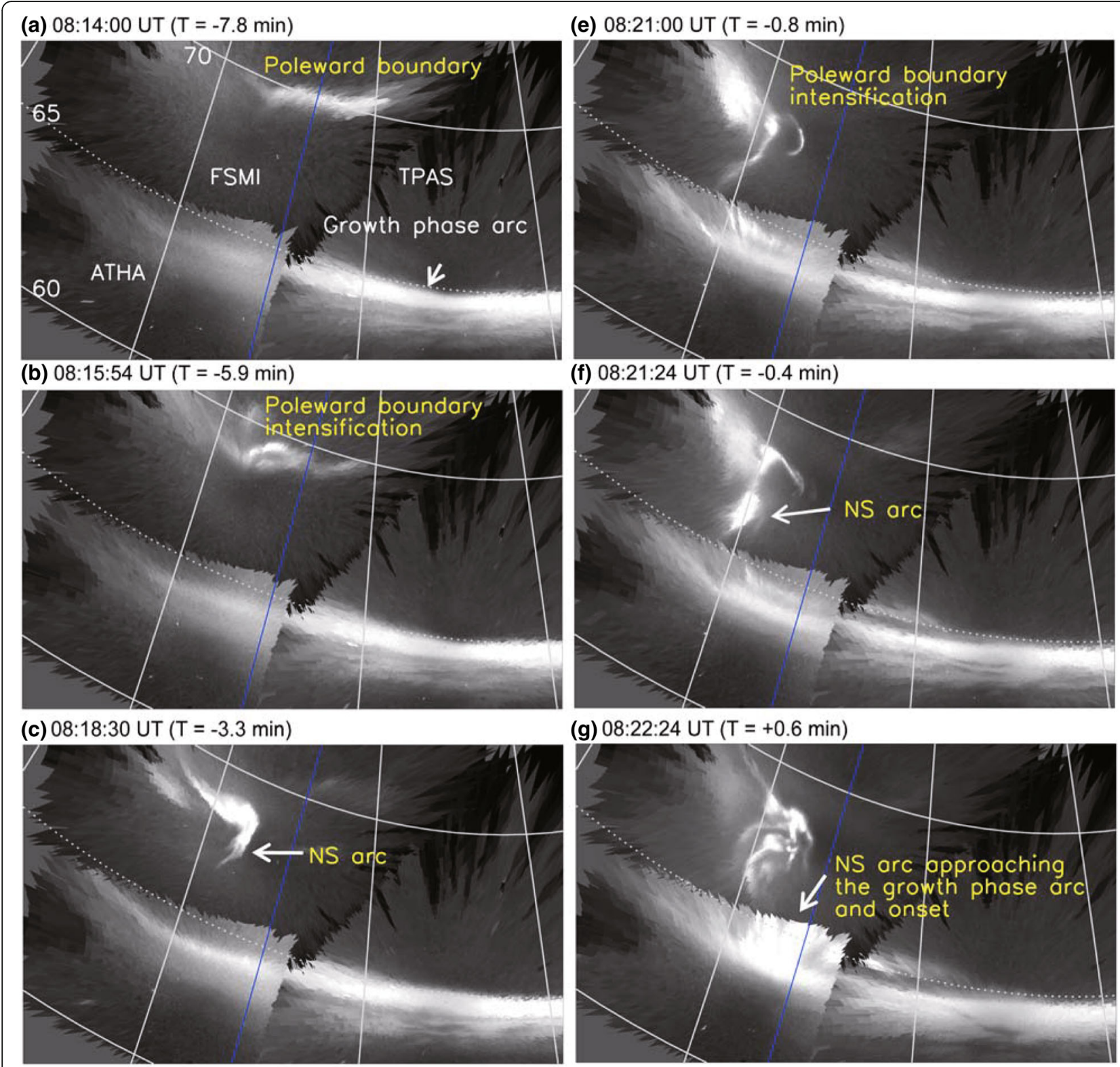

(g) 08:22:24 UT ( $T=+0.6 \mathrm{~min})$
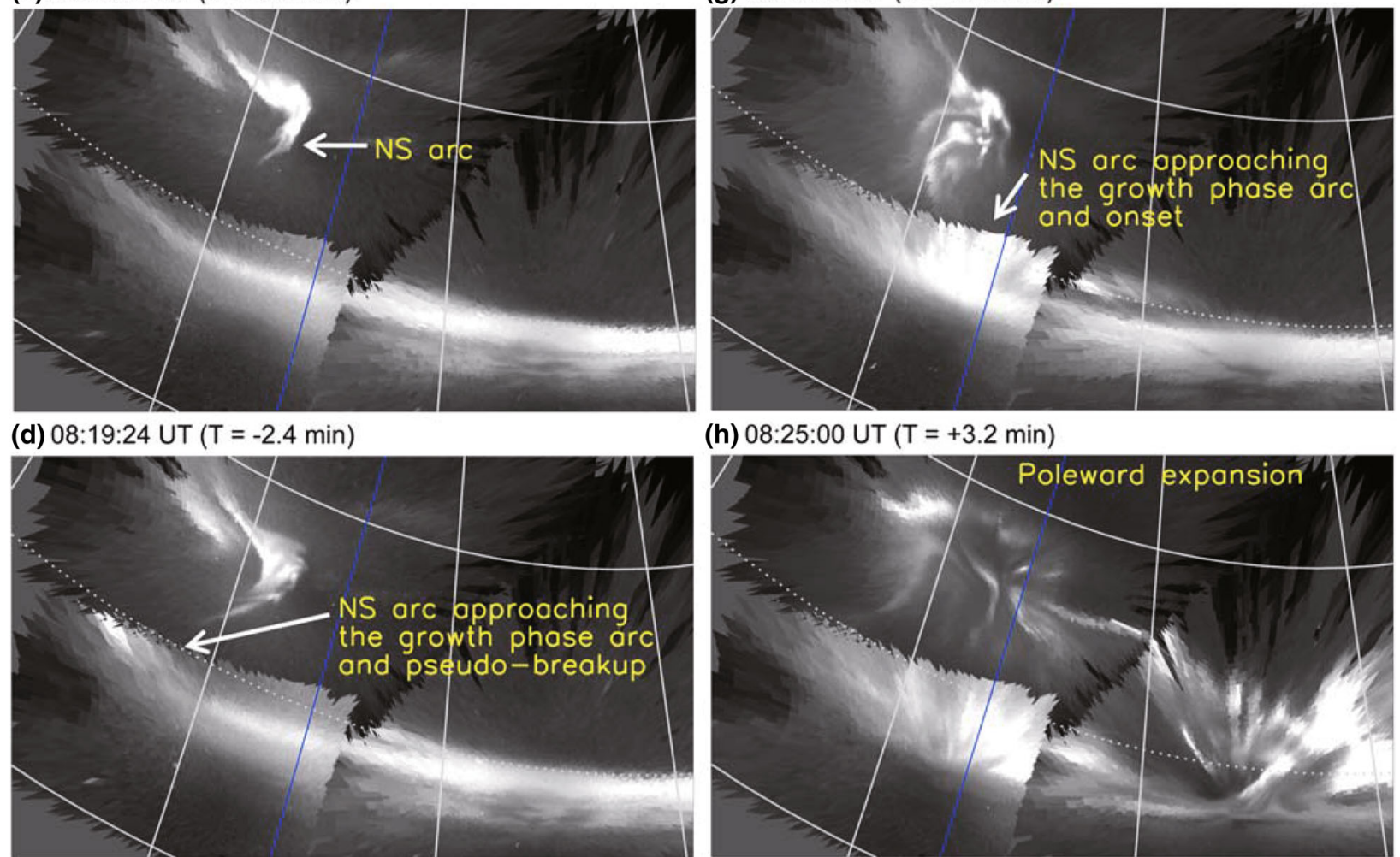

Fig. 7 a-h Observed high-latitude aurora moving equatorward. Auroral images observed at different sites are mapped to the ionosphere altitude. (Adapted from Nishimura et al. 2010) 
(a) Plasma pressure

(b) Parallel current

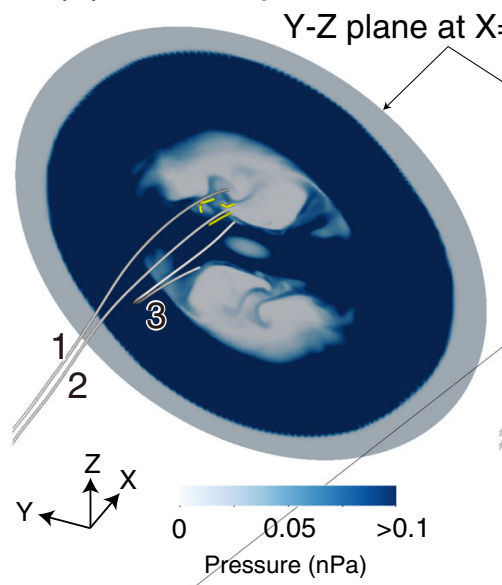

$-7 \mathrm{Re}$

(c) Parallel current

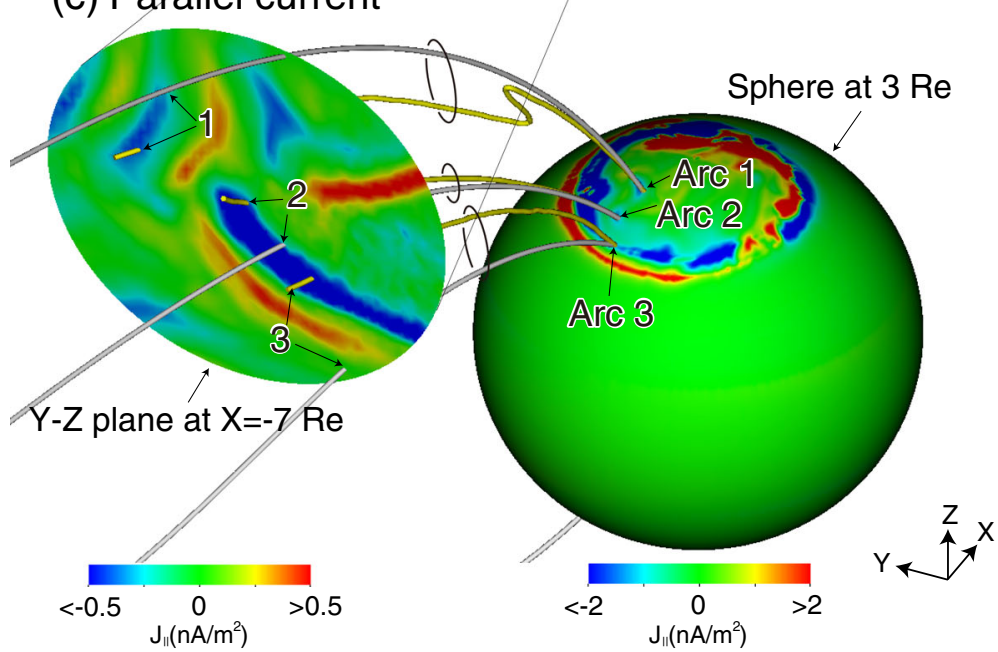

Fig. 8 a Plasma pressure and $\mathbf{b}$, c parallel current density in the $Y$ - $Z$ plane at $X=-7$ Re. In $\mathbf{c}$, parallel current is also drawn on the surface at 3 Re. The yellow and white lines indicate the current line and the magnetic field line, respectively, extending from Arcs 1, 2 (high-latitude aurora), and 3 (quiet arc) at $T=43.7 \mathrm{~min}$. The color codes indicate the parallel current density (negative upward in the Northern Hemisphere). (Adapted from Ebihara and Tanaka 2016)

(Nishida and Nagayama 1973; Angelopoulos et al. 1994; Baker et al. 1996; Nagai et al. 1998; Machida et al. 2009). Using the same simulation code with different solar wind parameters, Tanaka et al. (2017a) suggested that the NENL appears at $\sim 17 \operatorname{Re}$ downtail. The reason why the NENL starts to appear here is not well known and requires further investigation.

An immediate consequence of the formation of the NENL is the earthward and tailward flows near the equatorial plane. The earthward flow, known as a bursty bulk flow (Angelopoulos et al. 1994), is diverted westward and eastward as it approaches the Earth, generating flow shear (vorticity). The flow shear near the equatorial plane is observed near the expansion onset (Keiling et al. 2009). A pair of FACs (Birn and Hesse 1991; Birn et al. 2004a) are generated near the flow shear (vorticity). Another type of flow shear appears off the equator (Ebihara and Tanaka 2015b). When the magnetic reconnection proceeds, the plasma originating in the lobe traverses the separatrix (the open-closed boundary of magnetic field lines) and moves into the closed field line region. As the plasma traverses the separatrix on the duskside (dawnside), it is immediately deflected westward (eastward), generating flow shear and upward (downward) FACs at off-equator. The equatorial shear and the off-equatorial shear are schematically drawn in Fig. 10. The spatiotemporal evolution of the magnetospheric flow is reviewed by Tanaka et al. (2017a) in detail.

The red lines in Fig. 10 schematically indicate the current line on the basis of result of the line integral of the current density vector (Ebihara and Tanaka 2015b; Tanaka, 2015; Tanaka et al. 2017a). In the global MHD 


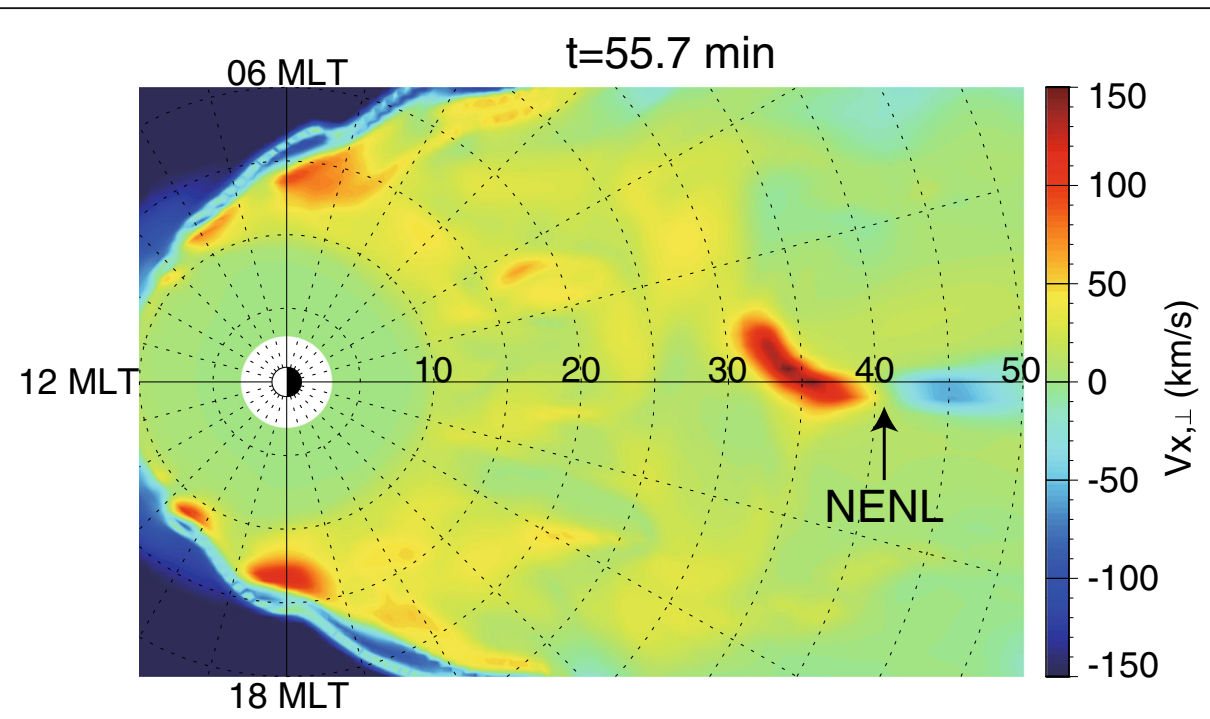

Fig. $9 X$-component of the perpendicular plasma flow velocity in the equatorial plane at $T=55.7 \mathrm{~min}$

simulation, three types of current can be defined: diamagnetic current, inertial current, and FAC. The diamagnetic current and the inertial current are given by

$$
\mathbf{J}_{d}=\frac{\mathbf{B} \times \nabla P}{B^{2}},
$$

and

$$
\mathbf{J}_{i}=\rho \frac{\mathbf{B}}{B^{2}} \times \frac{d \mathbf{V}_{\perp}}{d t},
$$

where $\rho, V_{\perp}$, and $P$ are the mass density, perpendicular velocity, and the plasma pressure, respectively. The sum of the three currents $\left(=\mathbf{J}_{d}+\mathbf{J}_{i}+\mathbf{J}_{\| \mid}\right)$is taken into account to draw the current line (Tanaka et al. 2010; Ebihara and Tanaka 2015b). It should be emphasized that current carriers, such as electrons and ions, do not necessarily move along the current line. The diamagnetic current is associated with the cyclotron motion of charged particles (Parker 1957), and the FAC is associated with field-aligned motion of the particles. Two types of

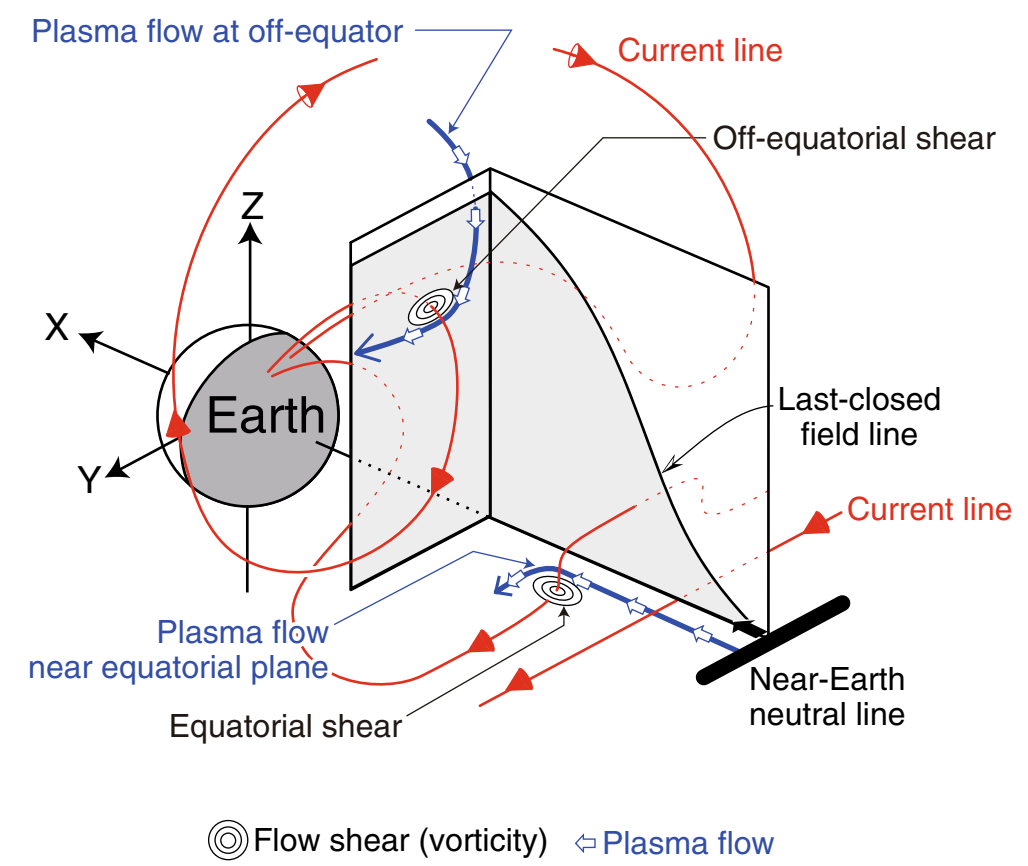

Fig. 10 A schematic of plasma flow (blue line), flow shear (triple circles), and current lines (red line) at the expansion onset 
current line are drawn in Fig. 10, which are closely associated with the expansion onset. One is found near the equatorial plane, which is wedge-like in form. The cross-tail current is diverted from the equatorial plane due to the FACs associated with the earthward plasma flow (Birn et al. 1999; Keiling et al. 2009). However, the leg of the wedge is too short to reach the ionosphere. The reason why the wedge-like current is incomplete is that the perpendicular current (mostly the diamagnetic current) overcomes the FAC, so that the current line is no longer field-aligned (Ebihara and Tanaka 2015b; Ebihara and Tanaka 2017). The intensification of the diamagnetic current is directly associated with an abrupt increase in the plasma pressure, which is often observed by geosynchronous satellites around the expansion onset (Birn et al. 1997). The abrupt increase in the plasma pressure is also observed in the nearEarth plasma sheet near the equatorial plane and off the equator (Yao et al. 2015a; Yao et al. 2015b). An observer can detect FACs near the equatorial plane (Nagai et al. 1987), but it does not always mean that the total current is parallel to the magnetic field line. Observations are required to confirm whether or not the current wedge is complete. The direction between the current density $\mathbf{J}$ and the magnetic field $\mathbf{B}$ will provide a significant clue in evaluating the dominance of the perpendicular current. Interestingly, the shortlegged incomplete current wedge is connected to the poleward half of the Region 2-like FAC that is newly developed during the substorm expansion (Ebihara et al. 2014). This current line is consistent with the theoretically obtained one (Roelof et al. 2004).

The other type of current is drawn in Fig. 10. This type of current is connected to the ionospheric location and is more directly related to the expansion onset for the following reasons (Ebihara and Tanaka 2015b; Ebihara and Tanaka 2017):

1. The rate of change in the FAC, which is given by

$$
\frac{\partial J_{\|}}{\partial t}=-\frac{(\nabla \times \nabla \times \mathbf{E})_{\|}}{\mu_{0}},
$$

is maximized at off-equator along the magnetic field line extending from the location of the expansion onset.

2. The generation of the FAC as expressed by Eq. (4) coexists with the dynamo region where $\mathbf{J} \cdot \mathbf{E}<0$.

3. The upward FAC region propagates towards the Earth along the onset field line with a significantly slower speed than the local Alfvén speed.
The last two items are direct evidence supporting the idea that the FACs are generated off the equator, rather than via the propagation of $J_{\|}$from the equatorial plane as an Alfvén wave. For better understanding of Eq. (4), the following approximation is suggested (Song and Lysak 2001a; Song and Lysak 2001b) as

$$
\frac{\partial J_{\|}}{\partial t} \approx \frac{\mathbf{B} \cdot \nabla \Omega_{\|}}{\mu_{0}}
$$

where $\Omega_{\|}\left(=(\nabla \times \mathbf{V})_{\|}\right)$is the vorticity of flow in the direction parallel to the magnetic field and $\mathbf{V}$ is the flow velocity. Equation (5) is confirmed to be valid for the expansion onset (Ebihara and Tanaka 2015b; Ebihara and Tanaka 2017) and implies that the gradient of the vorticity along the field line generates the FAC. This vorticity gradient is the flow coming from the lobe region towards the equatorial plane as schematically drawn in Fig. 10. The flow is diverted to westward (eastward) off the equator, so as to generate the flow shear (vorticity), and the upward (downward) FAC. The off-equatorial flow shear in the $Y-Z$ plane has been observed by the Cluster satellite during dipolarization (Nakamura et al. 2014).

Figure 11 shows a schematic of the stream lines projected onto the meridional plane. Two types of stream line are shown. One travels near the equator (the equatorial path), which is accompanied by bursty bulk flow and flow braking, and is associated with the equatorial flow shear shown in Fig. 10. The other travels off the equator (the off-equatorial path). The off-equatorial path is associated with the off-equatorial shear. Both the stream lines participate in the generation of shear and FACs, but the off-equatorial path is more directly related to the expansion onset in the ionosphere as illustrated above, according to the REPPU code.

When the strong upward FAC reaches the ionosphere, the auroral substorm expansion begins. It begins near the equatorward border of the preexisting aurora as shown in Fig. 2 ( $T=69.4 \mathrm{~min})$. This is consistent with observation (Akasofu 1964). The reason why the upward FAC starts to be intensified near the equatorward border of the preexisting aurora is that the lobe plasma

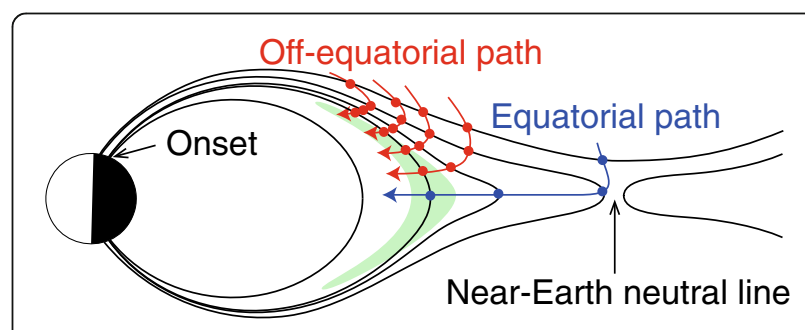

Fig. 11 A schematic of stream lines of plasma at expansion onset. The blue line indicates the stream line flowing near the equatorial plane. The red line indicates the stream line flowing at off-equator 
traverses the separatrix (open-closed boundary) and penetrates deep into the inner magnetosphere (Ebihara and Tanaka 2015a; Ebihara and Tanaka 2015b) as schematically drawn in Figs. 10 and 11. The simulated initial brightening is longitudinally elongated. This is also consistent with observation (Akasofu 1964). However, fine-scale structures such as a distinct ray structure (Akasofu 1964), a quasi-periodic series of bright spots, or beads (Elphinstone et al. 1995; Henderson 2009; Rae et al. 2010) are not present in the simulation results. The ballooning mode instability is the most plausible mechanism for the quasi-periodic series of bright spots, or beads (Elphinstone et al. 1995; Liang et al. 2008). An interesting result was obtained from the global MHD simulation, with balloon-like fine-scale structures appearing in the magnetotail (Raeder et al. 2012). Further investigations are necessary to investigate these structures.

\section{Expansion phase}

After the initial brightening of the aurora, a bulge forms around midnight, which expands poleward, westward, and eastward (Akasofu, 1964). Following the formation of the bulge, folds of aurora appear, moving westward rapidly. This is called a westward traveling surge (WTS). It is pointed out that the bulge dominantly expands westward, or eastward, depending on the polarity of the IMF $B_{\mathrm{y}}$ (Liou et al. 2006; Liou and Ruohoniemi 2006). The surge is clearly identified in the bulge that is expanding westward, whereas it is not clear in the eastward expanding bulge. Satellite observations show that the WTS is caused by precipitation of electrons downwardly accelerated to $\sim 10 \mathrm{keV}$ (Rème and Bosqued 1973; Meng et al. 1978). Intense upward FACs accompany the WTS (Kamide and Akasofu 1975; Fujii et al. 1994). The ionospheric counterpart of the intense FACs is thought to be connected to the auroral electrojet near the region where the ionospheric conductivity gradient is high (Inhester et al. 1981; Baumjohann et al. 1981). Partial blockage of the ionospheric Hall current is suggested as the cause of the buildup of excess charge near the surge, which distorts the ionospheric electric field near the surge (Kan et al. 1984). Electron-ion recombination effects may also play a role in modulating the intensity of the FACs (Rothwell et al. 1984). The magnetospheric counterpart of the intense FACs is suggested to be connected to the current wedge (CW) system (Fujii et al. 1994; Birn and Hesse 1996; Keiling et al. 2009). The WTS is also suggested to be a projection of the structure in the vicinity of the boundary between the tail lobe and the plasma sheet (Akasofu et al. 1971; Bythrow and Potemra 1987). Shear instability grows in the plasma sheet boundary layer, resulting in the intrusion of the plasma sheet into the tail lobe.
In the global MHD simulation, the auroral structures that resemble the bulge and the WTS appear as shown in Fig. 2. Based on the simulated WTS, Ebihara and Tanaka (2015a, 2018) suggest that the WTS is caused by the mutual interaction between the magnetosphere and the ionosphere. Figure 12 summarizes the FAC in the ionosphere, the nondiagonal component of the ionospheric conductivity, and the magnetospheric plasma pressure mapped to the ionosphere. A surge head (as manifested by the upward FAC) is situated in the westward-most area of the strong upward FAC region that is elongated in the east-west direction. In the REPPU code, the ionospheric conductivity is intensified in the regions where the upward FAC flows and where the magnetospheric plasma pressure is high. The former is a proxy of the discrete aurora, and the latter is a proxy of the diffuse aurora. It can clearly be seen in Fig. 12b that ionospheric conductivity is intensified near the surge head (where the upward FAC is high as shown in Fig. 12a), and the main body of the auroral bulge where the magnetospheric plasma pressure is high (as shown in Fig. 12c, as in the diffuse aurora). This is consistent with satellite observation (Meng et al. 1978).

The yellow contour in Fig. 12a indicates the region where the divergence of the electric field is positive $(\nabla \cdot \mathbf{E}>0$, where $\mathbf{E}$ is electric field), which coincides with the surge head. The divergence of the electric field is negative $(\nabla \cdot \mathbf{E}<0)$ on the backside of the surge as indicated by the red contour. The positive divergence and the negative divergence give rise to the development of positive and negative space charge, respectively. Due to the space charge represented by $\nabla \cdot \mathbf{E}$, the pattern of the convection is skewed near the surge. The convection flow tends to be counterclockwise near the surge head due to a positive space charge, whereas it tends to be clockwise on the backside of the surge due to a negative one. The skewed pattern of the convection around the surge head is similar to that suggested by Weimer et al. (1994).

Figure 13 shows $\nabla \cdot \mathbf{J}_{\mathrm{H}}, \nabla \cdot \mathbf{J}_{\mathrm{P}}$ and $\left(\nabla \cdot \mathbf{J}_{\mathrm{H}}+\nabla \cdot \mathbf{J}_{\mathrm{P}}\right) /\left|\nabla \cdot \mathbf{J}_{\mathrm{H}}\right|$, where $\mathbf{J}_{\mathrm{P}}$ and $\mathbf{J}_{\mathrm{H}}$ are the ionospheric Pedersen and the Hall currents, respectively. (The periodic structures at 67-68 MLATs come from a numerical error.) The solid contour line indicates the upward FAC, and the dashed one indicates the downward one. $\nabla \cdot \mathbf{J}_{\mathrm{H}}$ is negative near the surge head, whereas $\nabla \cdot \mathbf{J}_{\mathrm{H}}$ is positive on the backside of the surge. This means that the Hall current overflows near the surge head. $\nabla \cdot J_{\mathrm{P}}$ is positive near the surge head, meaning that a part of the Hall current is connected to the Pedersen current. The bottom panel of Fig. 13 indicates the ratio of $-\nabla \cdot \mathbf{J}_{\|}$to $\left|\nabla \cdot \mathbf{J}_{H}\right|$ (because $-\nabla \cdot \mathbf{J}_{\|}=\nabla \cdot \mathbf{J}_{H}$ $\left.+\nabla \cdot \mathbf{J}_{\mathrm{P}}\right)$, suggesting that most of the Hall current $(\sim 90 \%)$ is connected to the upward FAC. This condition can be regarded as a partial blockage of the Hall current as suggested by Kan et al. (1984). A small amount of the 


\section{$\mathrm{T}=74.5 \mathrm{~min}$}

(a) Field-aligned current

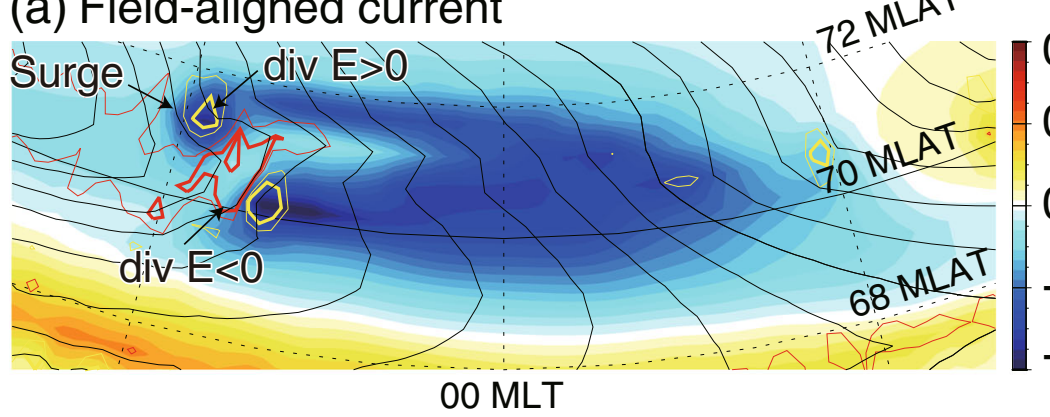

$00 \mathrm{MLT}$ (b) Ionospheric conductivity

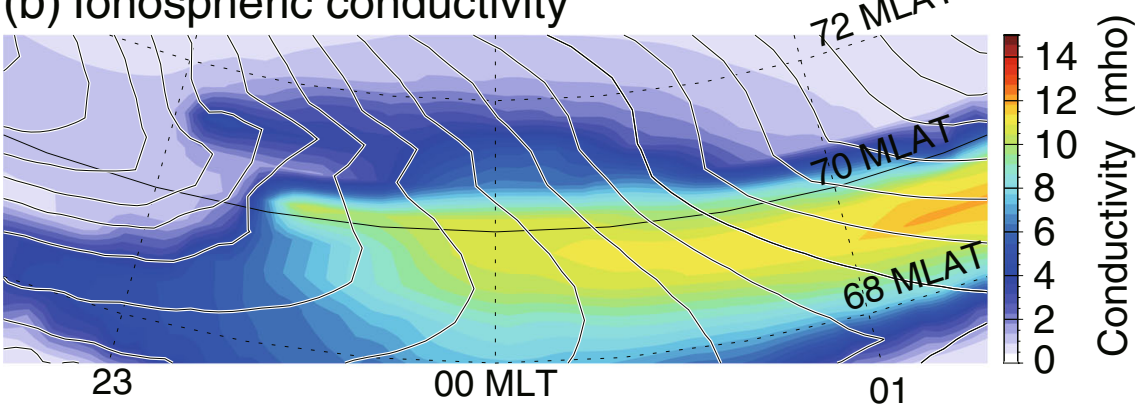

(c) Pressure

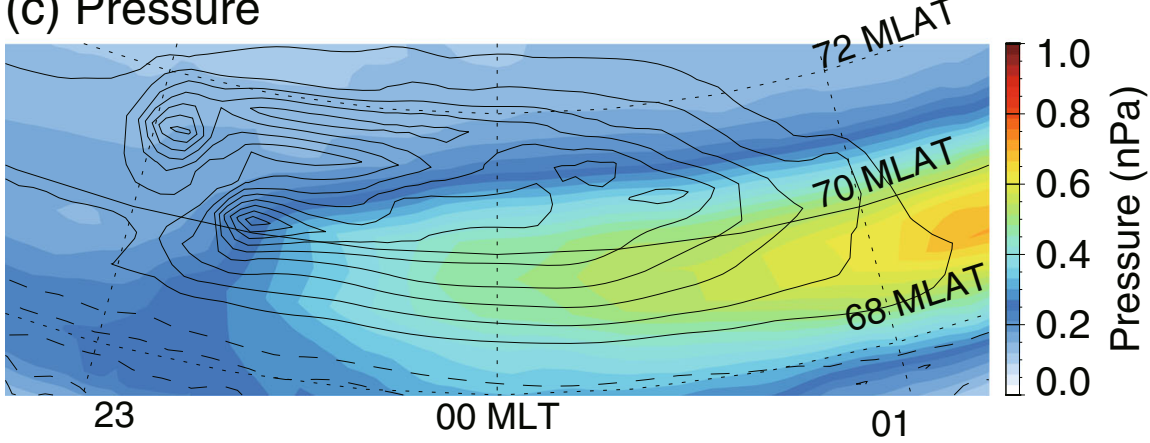

Fig. 12 a. Close-up views of the FACs, $\mathbf{b}$. the ionospheric conductivity, and $\mathbf{c}$. the magnetospheric pressure mapped to the ionosphere at $T=$ $74.5 \mathrm{~min}$. In $\mathbf{a}$., the yellow and red contour lines indicate the region where $\nabla \cdot \mathbf{E}$ is positive $\left(0.3 \mu \mathrm{V} / \mathrm{m}^{2}\right.$ for thick line and $0.15 \mu \mathrm{V} / \mathrm{m}^{2}$ for thin line) and $\nabla \cdot \mathbf{E}$ is negative $\left(-0.3 \mu \mathrm{V} / \mathrm{m}^{2}\right.$ for thick line and $-0.15 \mu \mathrm{V} / \mathrm{m}^{2}$ for thin line), respectively. $\mathbf{E}$ is the ionospheric electric field. The contour line in $\mathbf{a}$ and b indicates the ionospheric electric potential at interval of $1 \mathrm{kV}$. The contour line in c indicates the FACs. (Adapted from Ebihara and Tanaka 2018)

positive charge remains in the ionosphere, which is responsible for generating the additional FAC. This means that the WTS will not develop if the blockage is perfect $\left(\nabla \cdot \mathbf{J}_{||}=-\nabla \cdot \mathbf{J}_{\mathrm{H}}\right)$. And what about the magnetospheric counterpart of the WTS? The upward FAC associated with the WTS is connected to the inertial current in the low-altitude magnetosphere, according to the REPPU code (Ebihara and Tanaka 2015a).

Figure 14 presents an illustration as an explanation. Let us suppose that a bright aurora occurs and that a Hall current traverses the bright aurora from right to left in the Northern Hemisphere. The intensity of the Hall current is larger in the bright aurora than in the general ambience because ionospheric conductivity is high in the bright aurora (Fig. 12b). Due to the gradient of this conductivity, the Hall current overflows in the red region where $\mathbf{J}_{\mathrm{H}} \cdot \nabla \Sigma_{\mathrm{H}}<0$, where $\Sigma_{\mathrm{H}}$ is the Hall conductivity. Positive space charge deposits (due to the partial blockage of the Hall current), giving rise to the condition that $\nabla \cdot \mathbf{E}>0$. The divergent electric field generates a counterclockwise flow in the low-altitude magnetosphere when the Earth is viewed from space. The counterclockwise flow gives rise to further intensification of the upward FAC, which results in a bright aurora near the surge head. The opposite processes take place on the trailing side of the surge where $\mathbf{J}_{\mathrm{H}} \cdot \nabla \Sigma_{\mathrm{H}}>0$. Lack of the Hall current results in a negative charge $(\nabla \cdot \mathbf{E}<0)$. The resulting clockwise flow weakens the upward FACs that 


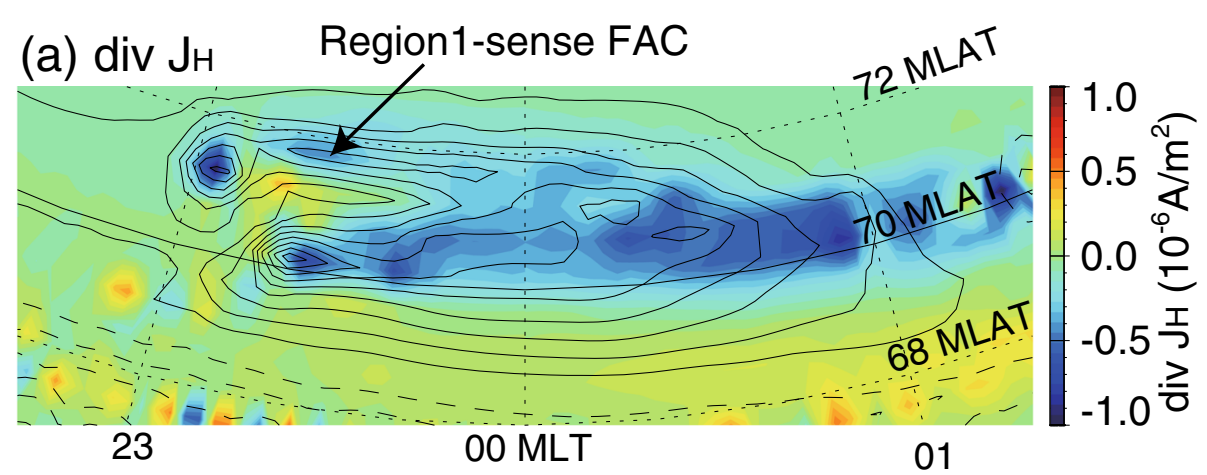

(b) $\operatorname{div} \mathrm{JP}$

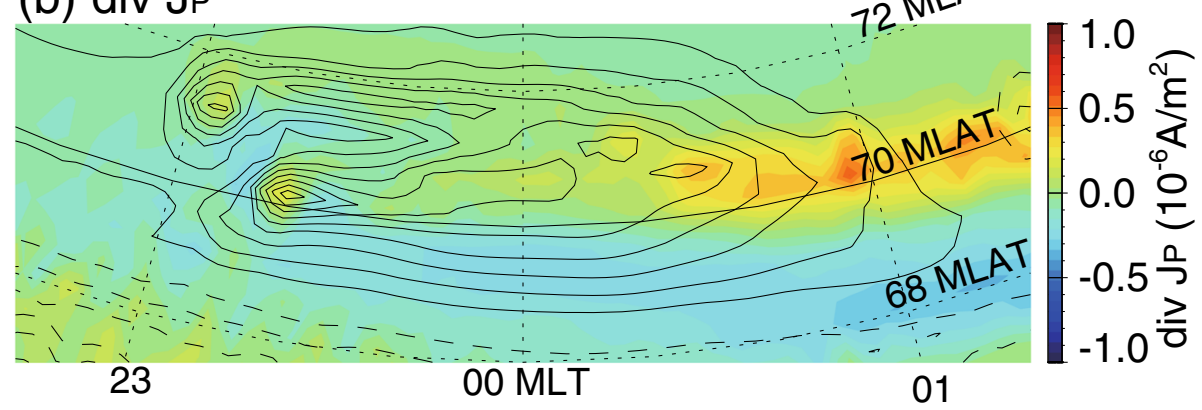

(c) $\left(\operatorname{div} \mathrm{JH}_{\mathrm{H}}+\operatorname{div} \mathrm{JP}\right) / \operatorname{ldiv} \mathrm{JH}_{\mathrm{H}}$

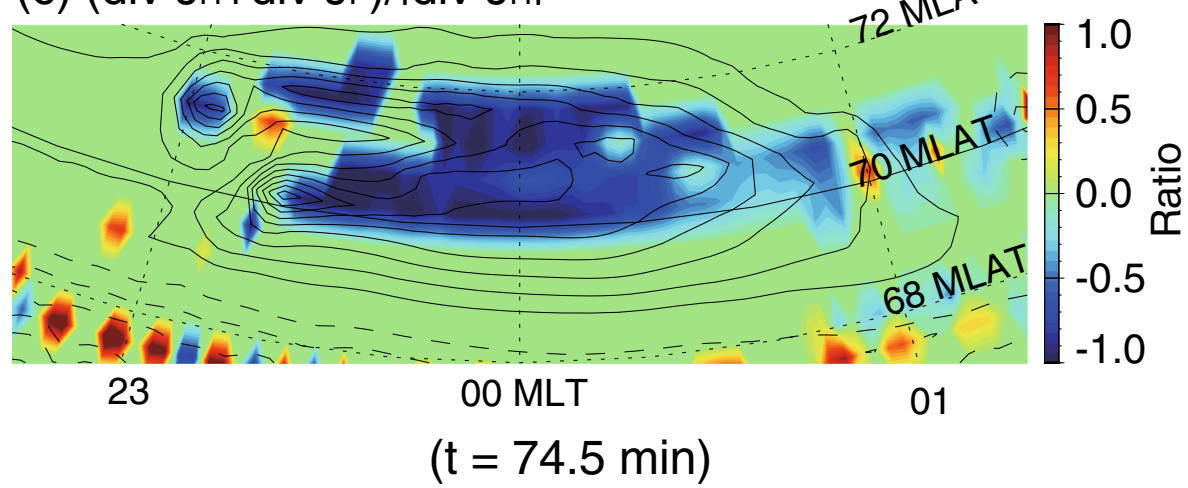

Fig. 13 a Divergence of the Hall current $\mathbf{J}_{H}$, b divergence of the Pedersen current $\mathbf{J}_{P}$, and $\mathbf{c}$ the ratio $\left(\operatorname{div} \mathbf{J}_{H}+\operatorname{div} \mathbf{J}_{P}\right) /\left|\operatorname{div} \mathbf{J}_{H}\right|\left(=-\operatorname{div} \mathbf{J}_{\|} /\left|\operatorname{div} \mathbf{J}_{H}\right|\right)$. The contour lines indicate the field-aligned current with an interval of $0.05 \mu \mathrm{A} / \mathrm{m}^{2}$. (Adapted from Ebihara and Tanaka 2015a)

had been intensified in the surge head. By repeating these processes, the WTS moves towards the direction of the Hall current. When one views the auroral breakup from space, it looks as if flames have spread rapidly over a sheet of paper. It can be said that ignition (near the surge head) and digestion (near the backside of the surge) take place simultaneously as the surge moves. The direction of the Hall current can be locally skewed by the space charge that deposits near the leading/trailing edges of the surge as a consequence of the partial blockage. The ratio of $-\nabla \cdot \mathbf{J}_{||}$to $\left|\nabla \cdot \mathbf{J}_{\mathrm{H}}\right|$ (shown in Fig. 13c) could determine the degree of the skew, but it is unclear what determines the ratio.

In reality, the bright aurora is caused by the precipitation of electrons accelerating downwards in the parallel electric field. The global MHD simulation cannot deal with electron kinetic processes, such as the formation of a parallel electric field. A complete explanation for the WTS will be obtained when the electron kinetic processes embedded in the global processes taking place in the magnetosphere are taken into consideration.

\section{Energy flow and conversion}

The Joule dissipation rate exceeds $10^{11} \mathrm{~W}$ in the ionosphere during substorm expansion (Ahn et al. 1983; Sun et al. 1985; Kamide et al. 1986; Richmond et al. 1990; Palmroth et al. 2005). We know that the ultimate source of the energy is solar wind. A number of studies have been conducted to relate the Joule dissipation rate 


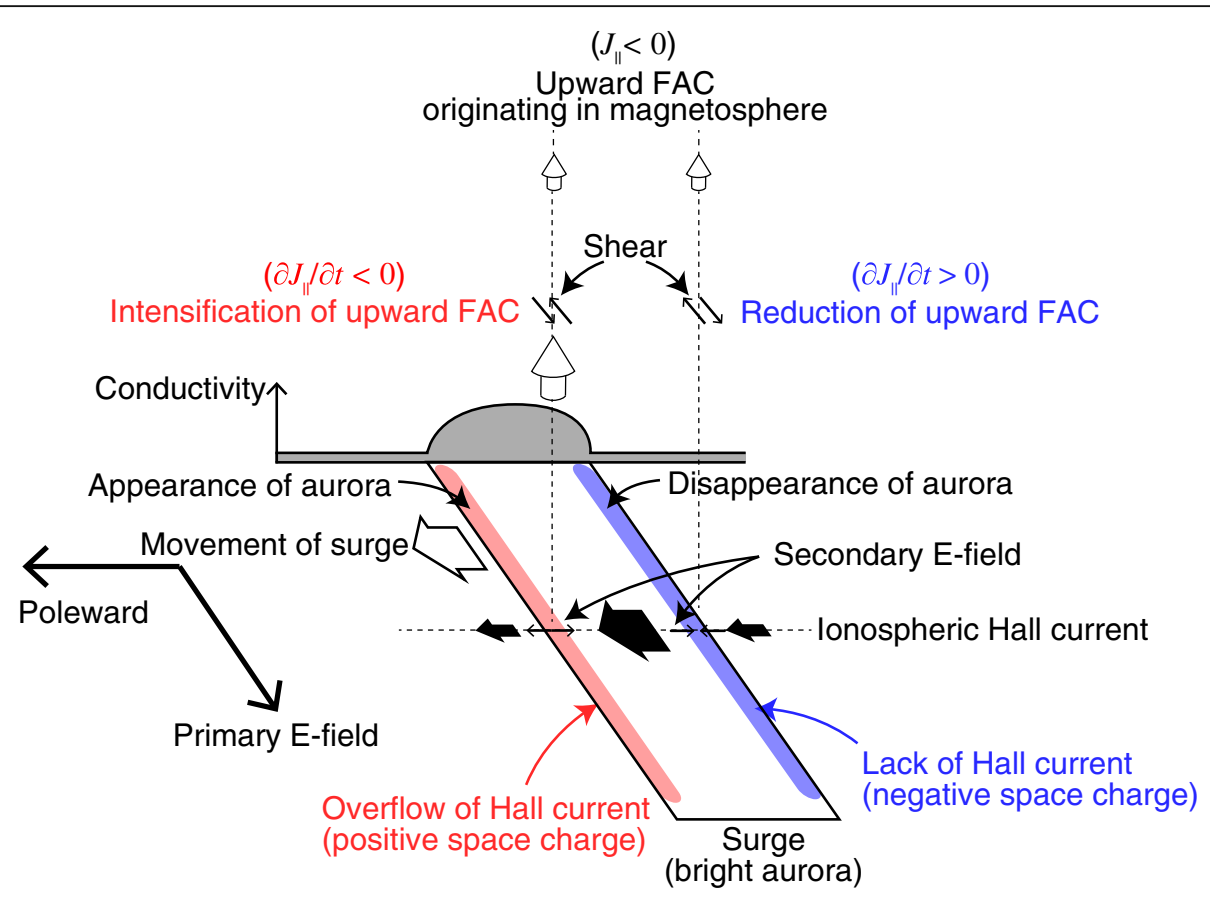

Fig. 14 Schematic drawing for the formation of the westward traveling surge. (Ebihara and Tanaka 2018)

to the solar wind energy input (Perreault and Akasofu 1978; Akasofu 1979; Baker et al. 1997; Koskinen and Tanskanen 2002). However, details of the pathway and the conversion of energy from the solar wind to the Earth are still problematic.
Ebihara and Tanaka (2017) suggested a way to represent the pathway of the electromagnetic energy from the solar wind to the ionosphere. The basis of this principle is to trace the Poynting flux $\mathbf{S}\left(=\mathbf{E} \times \mathbf{B} / \mu_{0}\right)$. The result is provided in Fig. 15. (The solar wind condition is

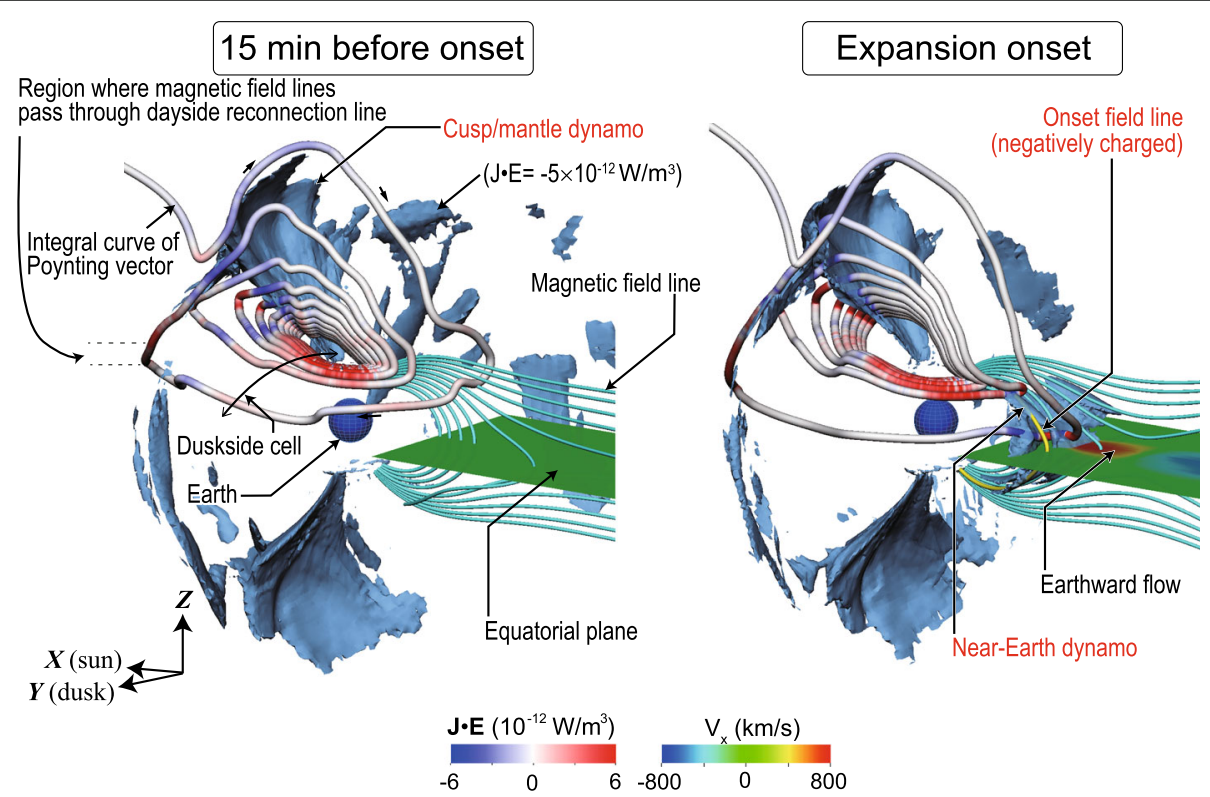

Fig. 15 The principal pathway of electromagnetic energy in the magnetosphere (as shown by the white line) at 15 min before onset (left panel) and at expansion onset (right panel). The blue shade indicates the region where $\mathbf{J} \cdot \mathbf{E}<0$ (dynamo region). The light blue line indicates the magnetic field line. The plane indicates the equatorial plane with color given by the $X$-component of the plasma flow. The yellow line stands for the magnetic field line extending from the onset location in the ionosphere. (Adapted from Ebihara and Tanaka 2017) 
different from that used in the other figures. After the southward turning of the IMF, the following parameters were used: a solar wind density of $5.0 \mathrm{~cm}^{-3}$, a solar wind speed of $500 \mathrm{~km} \mathrm{~s}^{-1}$, an IMF $B_{\mathrm{y}}$ of $-2.5 \mathrm{nT}$, and an IMF $B_{\mathrm{z}}$ of $-5 \mathrm{nT}$.) The integral curve of the Poynting flux is given by $\int \mathbf{S} \cdot d s / S$, where $s$ is a line element. This is called an $S$-curve (Ebihara and Tanaka 2017). The color on the $\mathrm{S}$-curve represents $\mathbf{J} \cdot \mathbf{E}$. The $S$-curve is a snapshot; it does not always represent propagation of the electromagnetic energy. The $S$-curve comes from the solar wind. As the S-curve passes through the bow shock, it meets the dynamo region located in the cusp and mantle. The cusp/mantle dynamo is responsible for driving the magnetospheric convection and the Region 1 FACs (Siscoe et al. 2000; Tanaka 2000a). The $S$-curve further travels tailward and towards the equatorial plane. It turns westward on the nightside and continues to extend sunward. Finally, it becomes a helix, which is like a cylindrical coil spring. The center of the helix moves towards the Earth. The earthward propagation of the $S$-curve is due to a twist of the magnetic field line in the presence of the large-scale FAC known as the Region 1 FAC (Iijima and Potemra 1976). The circular curve around the center of the helix is a manifestation of magnetospheric convection. At the expansion onset, an additional dynamo region appears in the near-Earth region (Birn and Hesse 2005; Ebihara and Tanaka 2015b; Tanaka 2015). This near-Earth dynamo is responsible for the generation of the FACs both at the onset and afterwards (Ebihara and Tanaka 2015b; Tanaka 2015; Ebihara and Tanaka 2017). The $S$-curve shows a sharp kink in the near-Earth region, which is a manifestation of the flow shear generating the upward FAC which thereby causes the onset of the expansion.

In the ideal MHD, three types of energy can be defined as follows (Birn and Hesse 2005). The first one is the electromagnetic energy represented by the Poynting flux $\mathbf{S}$ as

$$
\begin{aligned}
\nabla \cdot \mathbf{S} & +\frac{\partial}{\partial t}\left(\frac{B^{2}}{2 \mu_{0}}\right)=-\mathbf{J} \cdot \mathbf{E} \\
& =-\mathbf{V}_{\perp} \cdot(\mathbf{J} \times \mathbf{B}) .
\end{aligned}
$$

The second one is the kinetic energy

$$
\frac{\partial}{\partial t}\left(\frac{\rho}{2} V^{2}\right)+\nabla \cdot\left(\frac{\rho}{2} V^{2} \mathbf{V}\right)=\mathbf{V} \cdot(\mathbf{J} \times \mathbf{B}-\nabla P) .
$$

The third one is the internal energy

$$
\frac{\partial u}{\partial t}+\nabla \cdot(\gamma u \mathbf{V})=\mathbf{V} \cdot \nabla P,
$$

where $\gamma$ is the ratio of specific heat $(=5 / 3)$. The kinetic energy flux $\mathbf{K}$ and the enthalpy flux $\mathbf{H}$ are given by

$$
\mathbf{K}=\frac{1}{2} \rho V^{2} \mathbf{V},
$$

and

$$
\mathbf{H}=\gamma u \mathbf{V},
$$

respectively. Ebihara and Tanaka (2017) investigated the principal conversion of energy associated with the expansion onset. Figure 16 summarizes the principal energy flow and conversion among $S, K$, and $H$.

1. $S$ and $K$ are accompanied by the solar wind.

2. In the magnetosheath, a part of $K$ that originated in the solar wind is converted to $H$. A small fraction of it is converted to $S$ (Tanaka et al. 2016).

3. When the IMF is southward, the cusp/mantle dynamo appears (Siscoe et al. 2000; Tanaka 2000a), which converts a part of $K$ to $S$.

4. In the lobe, a part of $S$ is stored in association with a partial stagnation of the convection as represented by $\nabla \cdot \mathbf{V}_{\perp}<0$ (Ebihara and Tanaka 2017).

5. After the formation of the NENL, $S$ stored in the lobe is released together with the continuously supplied $S$ from the cusp/mantle dynamo and the solar wind (Ebihara and Tanaka 2017).

6. In the vicinity of the NENL, $S$ originating in the lobe splits to $K$ and $H$ (Birn et al. 2010).

7. In the plasma sheet, $K$ associated with earthward flow is converted to $H$ and $S$ due to the compression associated with flow braking (Birn and Hesse 2005; Ebihara and Tanaka 2017).

8. In the plasma sheet, $H$ propagates earthward along a field line (Tanaka et al. 2010).

9. Off the equator, $S$ originating in the lobe is converted to $H$ due to compression. Then, $H$ is converted to $K$, followed by $S$ (Ebihara and Tanaka 2017).

10. Off the equator, $S$ propagates earthward along a field line due to the FACs associated with the nearEarth dynamo.

Traditionally, two processes have been suggested for the energy transfer. One is the directly driven process (Perreault and Akasofu 1978; Akasofu 1979), and the other is the loading-unloading process (McPherron 1970; Mcpherron et al. 1973; Hones 1979). In the context of electromagnetic energy, the directly driven process is associated with the energy originating from the solar wind and that released from the cusp/mantle dynamo. The loading-unloading process is the energy storage and release in the lobe. The simulation result shows that both the energy sources merge together in the lobe during the expansion phase (Ebihara and Tanaka 2017). This means that the directly driven process also participates in the generation of the FACs, 


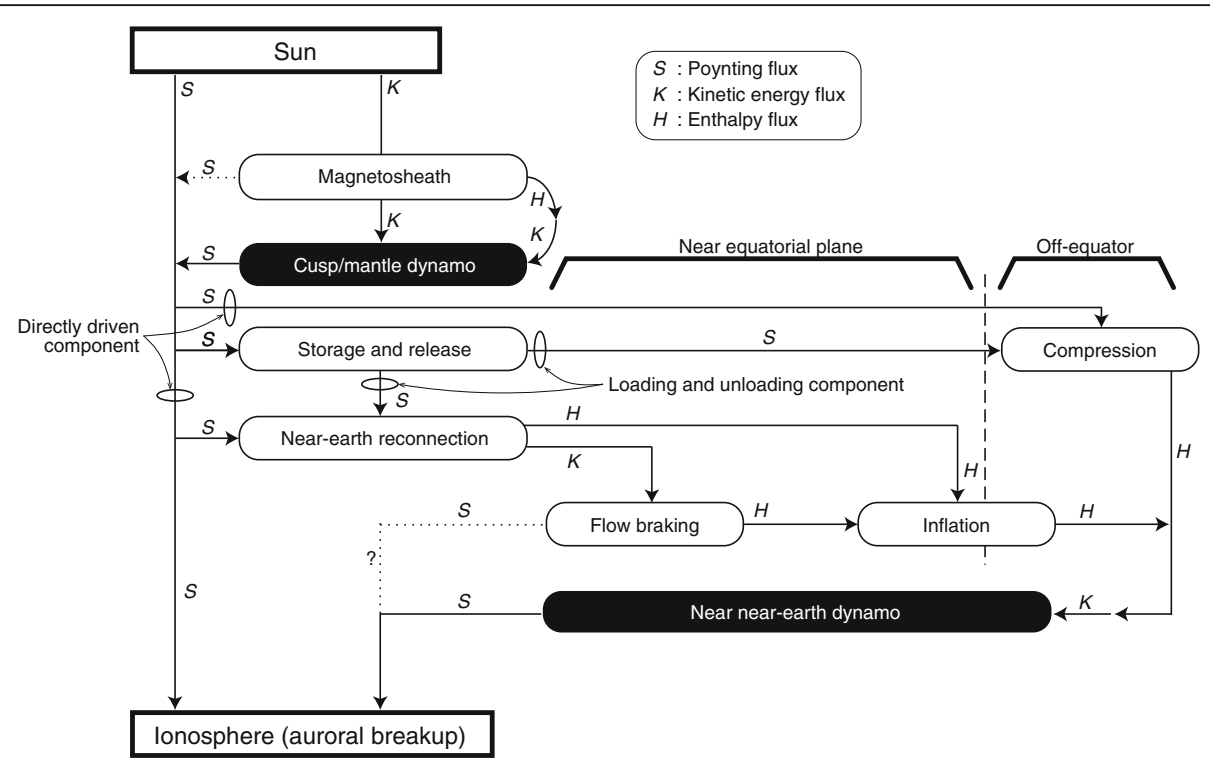

Fig. 16 Possible energy conversion from the Sun to the ionosphere at the expansion onset. $S, K$, and $H$ represent the Poynting flux, the bulk kinetic energy flux, and the enthalpy flux, respectively. The filled blocks indicate the cusp/mantle dynamo (Tanaka 2000a) and the near-Earth dynamo (Tanaka 2015, Ebihara and Tanaka 2015b)

which deliver electromagnetic energy to the ionosphere during substorm expansion. The energy consumed in the ionosphere is not fully sustained by the energy released from the lobe. This is consistent with the observation showing that the substorm size is largely controlled by the directly driven processes (Tanskanen et al. 2002). Akasofu (2013) pointed out that the energy stored in the lobe is insufficient to sustain the energy consumed in the ionosphere. The simulation result may settle this argument.

As inspired by the illustration of Akasofu (2015), the concept of the energy transfer from the solar wind to the ionosphere is schematically shown in Fig. 17. The water (energy) is supplied through a tube. The rate of flow in the tube is regulated by a valve. The valve is widely opened when the southward component of the IMF is strong, and the solar wind speed is high. After passing through the valve, some of the water flow turns the first watermill (cusp/mantle dynamo) that generates electromagnetic energy to light bulb 1 (quiet arc). The Region 1 FACs (associated with the cusp/mantle dynamo) are responsible for guiding the electromagnetic energy to the ionosphere. After passing through the first watermill (cusp/mantle dynamo), some of the water goes into a water bucket. Water coming directly from the tube also goes into the water bucket. When the bucket is filled up with water, it is tilted so as to release the water. The released water flows out, turning the second watermill (near-Earth dynamo). It is emphasized that the water directly coming from the first watermill and the tube also turn the second watermill. The second watermill generates electromagnetic energy to light bulb 2 (initial brightening). The Region-1 sense FACs (associated with the near-Earth dynamo) are responsible for guiding the electromagnetic energy to the ionosphere. Two photoresistors are serially connected to the bulbs 3 and 4 . The photoresistor is an electronic device in which resistance decreases with the increasing intensity of an incident light. When the photoresistor serially connected to bulb 3 detects light coming from bulb 2, its resistivity decreases, lighting bulb 3 . Subsequently, when the photoresistor serially connected to bulb 4 detects light coming from bulb 3 , its resistivity decreases, lighting bulb 4 . The final chain reaction (bulbs 2,3 , and 4 ) is analogous to the surge traveling westward.

Table 1 summarizes characteristics of the typical auroral structures that can be seen during a substorm from the growth phase to the expansion phase, together with possible causes of the auroral structure as suggested by the global MHD simulation. It seems that these auroral structures can be reasonably explained by the MHD processes coupled with the ionosphere. To date, fine-scale structures, such as distinct ray structures (Akasofu 1964) or quasi-periodic series of bright spots or beads (Elphinstone et al. 1995; Henderson 2009; Rae et al. 2010) are not resolved by the MHD model. Kinetic simulations will be needed to explain the fine-scale structures of the aurora.

\section{Conclusion}

Large- and meso-scale structures of the aurora that evolve during the substorm can be reasonably reproduced using 


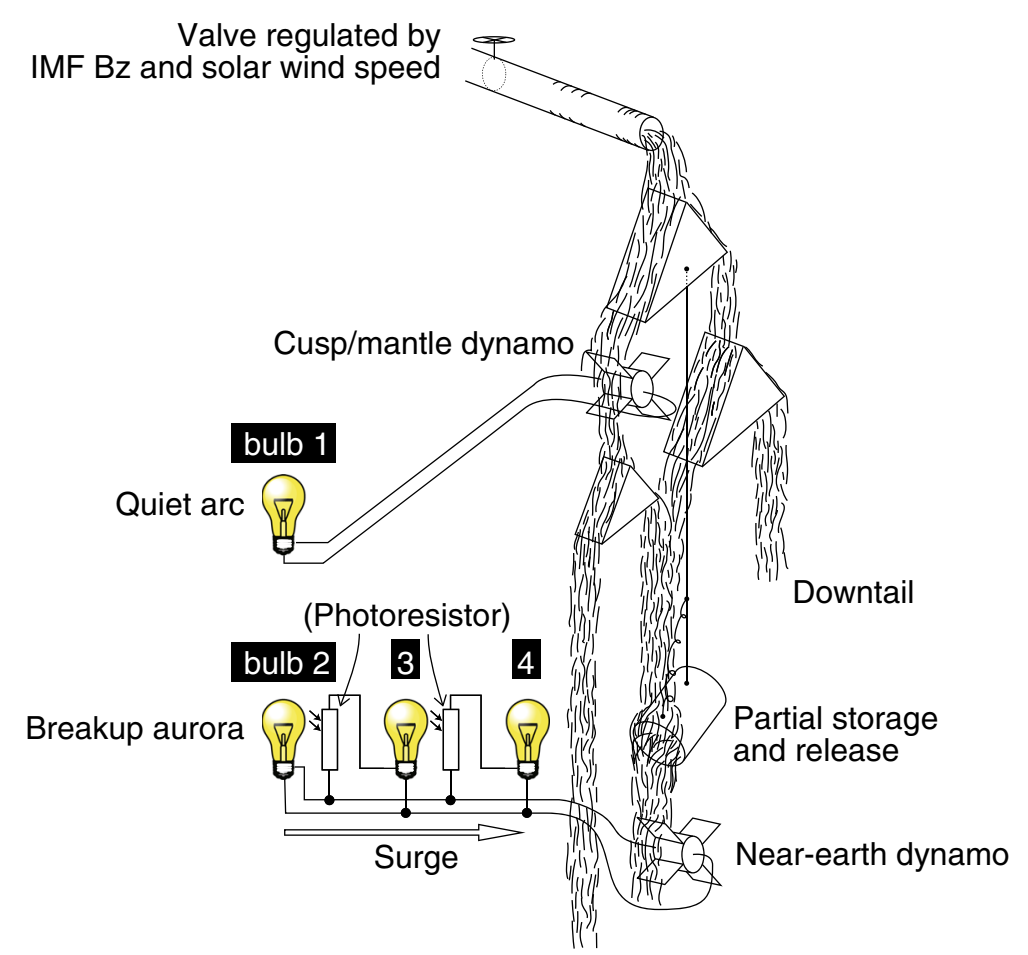

Fig. 17 Conceptual illustration of the possible chain reaction of auroral substorm in terms of energy transfer from the solar wind to the ionosphere. The quiet arc (bulb 1) is associated with the cusp/mantle dynamo. The breakup aurorae (bulbs 2, 3, and 4) are connected to the near-Earth dynamo. Illustration is based on Akasofu (2015)

the global MHD simulation (Tanaka 2015; Ebihara and Tanaka 2015a, 2015b, 2016; Tanaka et al., 2017a, b). During the growth phase, a quiet arc and high-latitude aurorae (found in the main auroral oval) appear in the simulation. The quiet arc is attributed to the flow shear off the equator. The high-latitude aurorae are attributed to fine structures in the plasma pressure distribution of the lobe region (open field line region). The expansion onset is triggered by the formation of a near-Earth neutral line (NENL). Plasma flow off the equator seems to be responsible for the generation of a field-aligned current that causes the onset of expansion. The initial brightening starts near the equatorward boundary of the preexisting aurora, which is consistent with observation. During the expansion phase, an excess of space charge near the bright aurora generates an additional field-aligned current, which manifests the westward traveling surge (WTS). Coupling between the magnetosphere and the ionosphere is essential for formation of the WTS. The energy consumed in the ionosphere during the expansion phase is not fully supplied by the lobe. The continuous supply of energy from the solar wind and the cusp/mantle dynamo also participates in the energy input into the ionosphere. Most importantly, the primary chain reactions from the solar wind to the WTS are reasonably explained by the MHD processes. Of course, contribution from non-MHD processes to the evolution of auroral substorms should be investigated in the future.

Fundamental properties and observable effects of the substorms came to be understood by numerical simulations. The next step is to understand the storm-substorm relationship by considering the comprehensive processes

Table 1 Cause and effect relationship for substorm-associated aurora as suggested by the global MHD simulation

\begin{tabular}{lll}
\hline $\begin{array}{l}\text { Substorm } \\
\text { phase }\end{array}$ & Characteristics of aurora & Possible cause \\
\hline $\begin{array}{l}\text { Growth } \\
\text { phase }\end{array}$ & Quiet arc & Flow shear at off-equator (Tanaka et al., 2017a) \\
& $\begin{array}{l}\text { High-latitude aurora within main } \\
\text { auroral oval }\end{array}$ & Non-linear interaction between magnetosphere and ionosphere (Ebihara and Tanaka 2016) \\
Onset & Initial brightening & Enhanced flow shear at off-equator (Ebihara and Tanaka 2015b) \\
Expansion & Westward traveling surge & $\begin{array}{l}\text { Coupling of partial blockage of Hall current and MHD magnetosphere (Ebihara and Tanaka 2015a; } \\
\text { Ebihara and Tanaka 2018) }\end{array}$ \\
\hline
\end{tabular}


occurring from the ionosphere to the solar wind. Such efforts have already begun (Fok et al. 2006; Welling et al. 2011; Glocer et al. 2011; Ouellette et al. 2013; Lotko et al. 2014; Nakayama et al. 2017). Substorms should influence the development of magnetic storms, and vice versa. In this sense, the magnetic storms and substorms are manifestations of magnetospheric and the ionospheric disturbances. Our goal should be to understand the overall system from the solar wind to the Earth. Obviously, the non-linear and complex system makes it difficult to understand the storm-substorm relationship quantitatively. Key processes include ionospheric ion outflow, the kinetics of auroral electron precipitation, global magnetospheric processes with multispecies plasmas, and non-adiabatic transport and acceleration. The numerical simulations, which are verified to be consistent with observations, are a powerful tool to help us. Mutual connections among the processes involved by the substorms are becoming clear. Some of them are probably applicable to the space environment near planets with an inherent magnetic field.

\section{Appendix}

The global magnetohydrodynamics (MHD) simulation developed by Prof. Takashi Tanaka, called a REPPU (REProduce Plasma Universe) code, solves a set of ideal MHD equations using the finite volume total variation diminishing (TVD) scheme (Tanaka 1994). The inner boundary is located on the sphere at a geocentric distance of $\sim 3 \mathrm{Re}$. Although the MHD equations are not solved in the region between the inner boundary and the ionosphere, the magnetosphere-ionosphere coupling is taken into consideration by exchanging quantities along the dipole magnetic field line. The following calculation is performed at every time step $(\sim 0.03 \mathrm{~s})$. First, the field-aligned current (FAC) and the plasma pressure at the inner boundary are mapped from the inner boundary of the magnetospheric domain to the ionosphere. Secondly, the ionospheric conductivities (Pedersen and Hall conductivities) are calculated on the basis of the mapped values (the FAC and the plasma pressure), and the solar zenith angle. The ionospheric conductivity is increased where the upward FACs flow and the plasma pressure is high. Thirdly, to satisfy the current continuity conditions in the ionosphere, an elliptic partial differential equation is solved for the given FACs and the ionospheric conductivity. The conjugate residual method was used to solve the partial differential equation. Fourthly, the electric field is mapped from the ionosphere to the inner boundary of the magnetospheric domain along the dipole magnetic field line. Fifthly, the velocity corresponding to the electric field is imposed on the inner boundary as one of the boundary conditions. For detailed explanations concerning this calculation, readers may refer to Tanaka 1994; Tanaka 1995; Tanaka, 2000a, b; Tanaka 2015).

The simulation employs a grid system having no singularity. A sphere with a radius of $\sim 3 \operatorname{Re}$ (where the inner boundary of the magnetospheric domain is located) is divided into 12 pentagons. Each pentagon is divided into five triangles. The number of the triangles is 60 . This is called Level 1. Each triangle is further divided into 4 triangles. This is called Level 2, in which the number of the triangles is 240 . We used Level 6 (61,440 triangles), or Level 7 (245,760 triangles). The triangular prisms are stacked outward from the inner boundary to the outer boundary located at $300 \mathrm{Re}$. For a detailed explanation of the grid system, readers may refer to Moriguchi et al. (2008).

The coordinate system is essentially the same as the Solar Magnetospheric coordinates. The $X$-axis points towards the Sun, and the $Z$-axis is anti-parallel to Earth's dipole moment. The $Y$-axis is defined as the cross-product of the $Z$ - and $X$-axes.

\section{Abbreviations}

CW: Current wedge; FAC: Field-aligned current

MHD: Magnetohydrodynamics; MLAT: Magnetic latitude; MLT: Magnetic local time; NENL: Near-Earth neutral line; REPPU: REProduce Plasma Universe

\section{Acknowledgements \\ The REPPU code was developed by Dr. Takashi Tanaka. A part of the computer simulation was performed on the KDK computer system at Research Institute for Sustainable Humanosphere, Kyoto University. The author thanks Drs. Atsuhiro Nishida, Takashi Tanaka, Takashi Kikuchi and Shin- Ichi Ohtani for fruitful discussion and valuable suggestion. \\ Funding \\ This work was supported by JSPS KAKENHI Grant Number $15 \mathrm{H} 03732$ and 15H05815, as well as Flagship Collaborative Research and Research Mission 3 "Sustainable Space Environments for Humankind" at RISH, Kyoto University.}

\section{Availability of data and materials}

This is a review paper. All data used here are in the original papers cited in the text except for Figs. 1 and 9. Data files for Figs. 1 and 9 are available at http://www2.rish.kyoto-u.ac.jp/ ebihara/2018-peps/.

Author's contributions

The author read and approved the final manuscript

Competing interests

The author declares that he has no competing interest.

\section{Publisher's Note}

Springer Nature remains neutral with regard to jurisdictional claims in published maps and institutional affiliations.

Received: 5 October 2018 Accepted: 8 February 2019

Published online: 05 March 2019

\section{References}

Ahn B-H, Robinson RM, Kamide Y, Akasofu S-I (1983) Electric conductivities, electric fields and auroral particle energy injection rate in the auroral ionosphere and their empirical relations to the horizontal magnetic disturbances. Planet Space Sci 31:641-653. https://doi.org/10.1016/00320633(83)90005-3

Akasofu S (2015) Auroral substorms as an electrical discharge phenomenon. Prog Earth Planet Sci 2:20. https://doi.org/10.1186/s40645-015-0050-9 
Akasofu SI (1968) Polar and magnetospheric substorms. D. Reidel Publ. Co., Dordrecht

Akasofu S-I (1964) The development of the auroral substorm. Planet Space Sci 12: 273-282. https://doi.org/10.1016/0032-0633(64)90151-5

Akasofu S-I (1979) Interplanetary energy flux associated with magnetospheric substorms. Planet Space Sci 27:425-431. https://doi.org/10.1016/00320633(79)90119-3

Akasofu S-I (2013) Where is the magnetic energy for the expansion phase of auroral substorms accumulated? J Geophys Res Sp Phys 118:7219-7225. https://doi.org/10.1002/2013JA019042

Akasofu S-I, Hones EW, Montgomery MD, Bame SJ, Singer S (1971) Association of magnetotail phenomena with visible auroral features. J Geophys Res 76: 5985-6003. https://doi.org/10.1029/JA076i025p05985

Akasofu S-I, Kimball DS, Meng C-I (1965) The dynamics of the aurora-II westward traveling surges. J Atmos Terr Phys 27:173-187. https://doi.org/10. 1016/0021-9169(65)90114-5

Akasofu S-I, Snyder AL (1972) Comments on the growth phase of magnetospheric substorms. J Geophys Res 77:6275. https://doi.org/10.1029/ JA077i031p06275

Allen JH, Kroehl HW (1975) Spatial and temporal distributions of magnetic effects of auroral electrojets as derived from AE indices. J Geophys Res 80:36673677. https://doi.org/10.1029/JA080i025p03667

Angelopoulos V, Kennel CF, Coroniti F V, Pellat R, Kivelson MG, Walker RJ, Russell CT, Baumjohann W, Feldman WC, Gosling JT (1994) Statistical characteristics of bursty bulk flow events density above the ion density They showed that fiir Extraterrestrische regardless activity [ Huang and Alamos National Laboratory, New The CPS was defined by Huang and

Antonova EE (1993) The development of initial substorm expansive phase disturbance due to generation of localized electric fields in the region of maximum upward field-aligned current. Adv Sp Res 13:261-264. https://doi. org/10.1016/0273-1177(93)90343-A

Atkinson G (1966) A theory of polar substorms. J Geophys Res 71:5157-5164. https://doi.org/10.1029/JZ071i021p05157

Baker DN, Pulkkinen TI, Angelopoulos V, Baumjohann W, McPherron RL (1996) Neutral line model of substorms: past results and present view. J Geophys Res 101:12975. https://doi.org/10.1029/95JA03753

Baker DN, Pulkkinen TI, Hesse M, McPherron RL (1997) A quantitative assessment of energy storage and release in the Earth's magnetotail. J Geophys Res Sp Phys 102:7159-7168. https://doi.org/10.1029/96JA03961

Baker DN, Pulkkinen TI, McPherron RL, Craven JD, Frank LA, Elphinstone RD, Murphree JS, Fennell JF, Lopez RE, Nagai T (1993) CDAW 9 analysis of magnetospheric events on May 3, 1986: Event C. J Geophys Res Sp Phys 98: 3815-3834. https://doi.org/10.1029/92JA02475

Baumjohann W, Pelunen RJ, Opgenoorth HJ, Nielsen E (1981) Joint twodimensional observations of ground magnetic and ionospheric electric fields associated with auroral zone currents: current systems associated with local auroral break-ups. Planet Space Sci 29:431-447. https://doi.org/10.1016/00320633(81)90087-8

Birn J, Borovsky JE, Hesse M, Schindler K (2010) Scaling of asymmetric reconnection in compressible plasmas. Phys Plasmas. https://doi.org/10.1063/1.3429676

Birn J, Hesse M (1991) The substorm current wedge and field-aligned currents in MHD simulations of magnetotail reconnection. J Geophys Res 96:1611-1618. https://doi.org/10.1029/90JA01762

Birn J, Hesse M (1996) Details of current disruption and diversion in simulations of magnetotail dynamics. J Geophys Res 101:15345. https://doi.org/10.1029/ 96JA00887

Birn J, Hesse M (2005) Energy release and conversion by reconnection in the magnetotail. Ann Geophys 23:3365-3373. https://doi.org/10.5194/angeo-233365-2005

Birn J, Hesse M (2014) The substorm current wedge: further insights from MHD simulations. J Geophys Res Sp Phys 119:3503-3513. https://doi.org/10.1002/ 2014JA019863

Birn J, Hesse M, Haerendel G, Baumjohann W, Shiokawa K (1999) Flow braking and the substorm current wedge. J Geophys Res 104:19895. https://doi.org/ 10.1029/1999JA900173

Birn J, Nakamura R, Panov EV, Hesse M (2011) Bursty bulk flows and dipolarization in MHD simulations of magnetotail reconnection. J Geophys Res Sp Phys 116:A01210. https://doi.org/10.1029/2010JA016083

Birn J, Raeder J, Wang YL, Wolf RA, Hesse M (2004a) On the propagation of bubbles in the geomagnetic tail. Ann Geophys 22:1773-1786. https://doi.org/ 10.5194/angeo-22-1773-2004
Birn J, Thomsen MF, Borovsky JE, Reeves GD, McComas DJ, Belian RD (1997) Characteristic plasma properties during dispersionless substorm injections at geosynchronous orbit. J Geophys Res 102:2309. https://doi.org/10.1029/ 96JA02870

Birn J, Thomsen MF, Borovsky JE, Reeves GD, McComas DJ, Belian RD, Hesse M (1998) Substorm electron injections: geosynchronous observations and test particle simulations. J Geophys Res Sp Phys 103:9235-9248. https://doi.org/ 10.1029/97JA02635

Birn J, Thomsen MF, Hesse M (2004b) Electron acceleration in the dynamic magnetotail: test particle orbits in three-dimensional magnetohydrodynamic simulation fields. Phys Plasmas 11:1825-1833. https://doi.org/10.1063/1. 1704641

Brittnacher M, Fillingim M, Parks G, Germany G, Spann J (1999) Polar cap area and boundary motion during substorms. J Geophys Res 104:12251. https:// doi.org/10.1029/1998JA900097

Bythrow PF, Potemra TA (1987) Birkeland currents and energetic particles associated with optical auroral signatures of a westward traveling surge. J Geophys Res 92:8691-8699. https://doi.org/10.1029/JA092iA08p08691

Chen CX, Wolf RA (1993) Interpretation of high-speed flows in the plasma sheet. J Geophys Res 98:21409-21419. https://doi.org/10.1029/93JA02080

Cheng CZ, Lui ATY (1998) Kinetic ballooning instability for substorm onset and current disruption observed by AMPTE/CCE. Geophys Res Lett 25:4091-4094. https://doi.org/10.1029/1998GL900093

Coroniti FV, Pritchett PL (2014) The quiet evening auroral arc and the structure of the growth phase near-Earth plasma sheet. J Geophys Res Sp Phys 119: 1827-1836. https://doi.org/10.1002/2013JA01943

Dahlgren $H$, Ivchenko N, Lanchester BS, Ashrafi M, Whiter D, Marklund G, Sullivan $J$ (2009) First direct optical observations of plasma flows using afterglow of in discrete aurora. J Atmos Solar-Terrestrial Phys 71:228-238. https://doi.org/ 10.1016/j.jastp.2008.11.015

Davis TN, Sugiura M (1966) Auroral electrojet activity index AE and its universal time variations. J Geophys Res 71:785-801. https://doi.org/10.1029/ JZ071i003p00785

DeForest SE, Mcllwain CE (1971) Plasma clouds in the magnetosphere. J Geophys Res 76:3587-3611. https://doi.org/10.1029/JA076i016p03587

Ebihara Y, Tanaka T (2013) Fundamental properties of substorm time energetic electrons in the inner magnetosphere. J Geophys Res Sp Phys 118:15891603. https://doi.org/10.1002/jgra.50115

Ebihara Y, Tanaka T (2015a) Substorm simulation: formation of westward traveling surge. J Geophys Res Sp Phys 120:10,466-10,484. https://doi.org/10. 1002/2015JA021697

Ebihara Y, Tanaka T (2015b) Substorm simulation: insight into the mechanisms of initial brightening. J Geophys Res Sp Phys 120:7270-7288. https://doi.org/10. 1002/2015JA021516

Ebihara Y, Tanaka T (2016) Substorm simulation: quiet and N-S arcs preceding auroral breakup. J Geophys Res Sp Phys 121:1201-1218. https://doi.org/10. 1002/2015JA021831

Ebihara Y, Tanaka T (2017) Energy flow exciting field-aligned current at substorm expansion onset. J Geophys Res Sp Phys. https://doi.org/10.1002/ 2017JA024294

Ebihara Y, Tanaka T (2018) Why does substorm-associated auroral surge travel westward? Plasma Phys Control Fusion. https:/doi.org/10.1088/1361-6587/aa89fd

Ebihara Y, Tanaka T, Kikuchi T (2014) Counter equatorial electrojet and overshielding after substorm onset: Global MHD simulation study. J Geophys Res Sp Phys 119:7281-7296. https://doi.org/10.1002/2014JA020065

El-Alaoui M, Ashour-Abdalla M, Walker RJ, Peroomian V, Richard RL, Angelopoulos $\checkmark$, Runov A (2009) Substorm evolution as revealed by THEMIS satellites and a global MHD simulation. J Geophys Res Sp Phys 114:n/a-n/a. doi: https://doi. org/10.1029/2009JA014133

Elphinstone RD, Hearn D, Murphree JS, Cogger LL (1991) Mapping Using the Tsyganenko Long Magnetospheric Model we relate the the model on the nightsid • This was chosen to 96:1467-1480

Elphinstone RD, Hearn DJ, Cogger LL, Murphree JS, Singer H, Sergeev V, Mursula K, Klumpar DM, Reeves GD, Johnson M (1995) Observations in the vicinity of substorm onset: implications for the substrom process. J Geophys Res 100: 7937-7969. https://doi.org/10.1029/94JA02938

Fairfield DH, Ness NF (1970) Configuration of the geomagnetic tail during substorms. J Geophys Res 75:7032-7047. https://doi.org/10.1029/ JA075i034p07032

Fedder JA, Slinker SP, Lyon JG, Elphinstone RD (1995) Global numerical simulation of the growth phase and the expansion onset for a substorm 
observed by Viking. J Geophys Res 100:19083. https://doi.org/10.1029/ 95JA01524

Fok MC, Moore TE, Brandt PC, Delcourt DC, Slinker SP, J a F (2006) Impulsive enhancements of oxygen ions during substorms. J Geophys Res Sp Phys 111: A10222. https://doi.org/10.1029/2006JA011839

Fujii R, Hoffman RA, Anderson PC, Craven JD, Sugiura M, Frank LA, Maynard NC (1994) Electrodynamic parameters in the nighttime sector during auroral substorms. J Geophys Res 99:6093. https://doi.org/10.1029/93JA02210

Glocer A, Fok M-C, Nagai T, Tóth G, Guild T, Blake J (2011) Rapid rebuilding of the outer radiation belt. J Geophys Res Sp Phys 116:n/a-n/a. doi: https://doi.org/ 10.1029/2011JA016516

Guo J, Liu H, Feng X, Pulkkinen TI, Tanskanen El, Liu C, Zhong D, Wang Y (2014) MLT and seasonal dependence of auroral electrojets: IMAGE magnetometer network observations. J Geophys Res Sp Phys 119:3179-3188. https://doi.org/ 10.1002/2014JA019843

Gurnett DA (1974) The Earth as a radio source: terrestrial kilometric radiation. J Geophys Res 79:4227-4238. https://doi.org/10.1029/JA079i028p04227

Haerendel G (1992) Disruption, ballooning or auroral avalanche-on the cause of substorms. In: Proceedings of the First International Conference on Substorms. ESA Publications Division, Kiruna, pp 417-420

Haerendel G (2008) Auroral arcs as current transformers. J Geophys Res Sp Phys 113:1-16. https://doi.org/10.1029/2007JA012947

Haerendel G (2010) Equatorward moving arcs and substorm onset. J Geophys Res 115:1-9. https://doi.org/10.1029/2009JA015117

Haerendel G, Frey HU, Chaston CC, Amm O, Juusola L, Nakamura R, Seran E, Weygand JM (2012) Birth and life of auroral arcs embedded in the evening auroral oval convection: a critical comparison of observations with theory. J Geophys Res Sp Phys 117:1-20. https://doi.org/10.1029/2012JA018128

Henderson MG (2009) Observational evidence for an inside-out substorm onset scenario. Ann Geophys 27:2129-2140. https://doi.org/10.5194/ angeo-27-2129-2009

Hesse M, Birn J (1991) On dipolarization and its relation to the substorm current wedge. J Geophys Res 96:19417. https://doi.org/10.1029/91JA01953

Hesse M, Birn J (1994) MHD modeling of magnetotail instability for localized resistivity. J Geophys Res 99:8565-8576. https://doi.org/10.1029/94JA00441

Hones EW (1979) Transient phenomena in the magnetotail and their relation to substorms. Space Sci Rev 23:393-410. https://doi.org/10.1007/BF00172247

Hones EW, Asbridge JR, Bame SJ, Singer S (1973) Substorm variations of the magnetotail plasma sheet from $X S M \approx-6 \mathrm{RE}$ to $X \mathrm{SM} \approx-60 \mathrm{RE}$. J Geophys Res 78:109-132. https://doi.org/10.1029/JA078i001p00109

Hones EW, Schindler K (1979) Magnetotail plasma flow during substorms: a survey with imp 6 and imp 8 satellites. J Geophys Res 84:7155. https://doi. org/10.1029/JA084iA12p07155

lijima T, Potemra TA (1976) The amplitude distribution of field-aligned currents at northern high latitudes observed by Triad. J Geophys Res 81:2165. https:// doi.org/10.1029/JA081i013p02165

Inhester B, Baumjohann W, Greenwald RA, Nielsen E (1981) Joint twodimensional observations of ground magnetic and ionospheric electric fields associated with auroral zone currents. III - auroral zone currents during the passage of a westward travelling surge. J Geophys 49:155-162

Ismail S, Wallis DD, Cogger LL (1977) Characteristics of polar cap Sun-aligned arcs. J Geophys Res 82:4741-4749. https://doi.org/10.1029/JA082i029p04741

Jiang F, Strangeway RJ, Kivelson MG, Weygand JM, Walker RJ, Khurana KK, Nishimura Y, Angelopoulos V, Donovan E (2012) In situ observations of the "preexisting auroral arc" by THEMIS all sky imagers and the FAST spacecraft. J Geophys Res Sp Phys 117:1-17. https://doi.org/10.1029/2011JA017128

Johnson ML, Murphree JS, Marklund GT, Karlsson T (1998) Progress on relating optical auroral forms and electric field patterns. J Geophys Res 103:4271. https://doi.org/10.1029/97JA00854

Kadokura A, Yukimatu AS, Ejiri M, Oguti T, Pinnock M, Hairston MR (2002) Detailed analysis of a substorm event on 6 and 7 June 1989 1. Growth phase evolution of nightside auroral activities and ionospheric convection toward expansion phase onset. J Geophys Res Sp Phys. doi: https://doi.org/10.1029/ 2001JA009127

Kamide $Y(1992)$ Is substorm occurrence a necessary condition for a magnetic storm? J Geomagn Geoelectr 44:109-117. https://doi.org/10.5636/jgg.44.109

Kamide Y, Akasofu S-I (1975) The auroral electrojet and global auroral features. J Geophys Res 80:3585. https://doi.org/10.1029/JA080i025p03585

Kamide Y, Craven JD, Frank LA, Ahn B-H, Akasofu S-I (1986) Modeling substorm current systems using conductivity distributions inferred from DE auroral images. J Geophys Res 91:11235. https://doi.org/10.1029/JA091iA10p11235
Kamide Y, Richmond AD, Emery BA, Hutchins CF, Ahn B-H, de la Beaujardiere O, Foster JC, Heelis RA, Kroehl HW, Rich FJ, Slavin JA (1994) Ground-based studies of ionospheric convection associated with substorm expansion. J Geophys Res 99:19451. https://doi.org/10.1029/94JA01625

Kan JR, Williams RL, Akasofu S-I (1984) A mechanism for the westward traveling surge during substorms. J Geophys Res 89:2211. https://doi.org/10.1029/ JA089iA04p02211

Keiling A, Angelopoulos V, Runov A, Weygand J, Apatenkov SV, Mende S, McFadden J, Larson D, Amm O, Glassmeier KH, Auster HU (2009) Substorm current wedge driven by plasma flow vortices: THEMIS observations. J Geophys Res Sp Phys. https://doi.org/10.1029/2009JA014114

Kepko L, Spanswick E, Angelopoulos V, Donovan E, McFadden J, Glassmeier K-H, Raeder J, Singer HJ (2009) Equatorward moving auroral signatures of a flow burst observed prior to auroral onset. Geophys Res Lett 36:L24104. https:// doi.org/10.1029/2009GL041476

Kim H-J, Chan AA, Wolf RA, Birn J (2000) Can substorms produce relativistic outer belt electrons? J Geophys Res 105:7721. https://doi.org/10.1029/ 1999JA900465

Korth H, Zhang Y, Anderson BJ, Sotirelis T, Waters CL (2014) Statistical relationship between large-scale upward field-aligned currents and electron precipitation. J Geophys Res Sp Phys 119:6715-6731. https://doi.org/10.1002/2014JA019961

Koskinen HEJ, Tanskanen El (2002) Magnetospheric energy budget and the epsilon parameter. J Geophys Res 107:1415. https://doi.org/10.1029/ 2002JA009283

Lassen K, Sharber JR, Winningham JD (1977) The development of auroral and geomagnetic substorm activity after a southward turning of the interplanetary magnetic field following several hours of magnetic calm. https://doi.org/10.1029/JA082i032p05031

Lessard MR, Lotko W, LaBelle J, Peria W, Carlson CW, Creutzberg F, Wallis DD (2007) Ground and satellite observations of the evolution of growth phase auroral arcs. J Geophys Res Sp Phys 112:1-17. https://doi.org/10.1029/ 2006JA011794

Liang J, Donovan EF, Liu WW, Jackel B, Syrjäsuo M, Mende SB, Frey HU, Angelopoulos V, Connors M (2008) Intensification of preexisting auroral arc at substorm expansion phase onset: wave-like disruption during the first tens of seconds. Geophys Res Lett 35:1-6. https://doi.org/10.1029/2008GL033666

Liou K (2010) Polar ultraviolet imager observation of auroral breakup. J Geophys Res 115:A12219. https://doi.org/10.1029/2010ja015578

Liou K, Meng C-I, Lui TY, Newell PT, Brittnacher M, Parks G, Reeves GD, Anderson RR, Yumoto K (1999) On relative timing in substorm onset signatures. J Geophys Res Sp Phys 104:22807-22817. https://doi.org/10.1029/ 1999JA900206

Liou K, Meng Cl, Wu CC (2006) On the interplanetary magnetic field by control of substorm bulge expansion. J Geophys Res Sp Phys 111:1-8. doi: https://doi. org/10.1029/2005JA011556

Liou K, Newell PT (2010) On the azimuthal location of auroral breakup: hemispheric asymmetry. Geophys Res Lett. https://doi.org/10.1029/ 2010GL045537

Liou K, Ruohoniemi JM (2006) A case study of relationship between substorm expansion and global plasma convection. Geophys Res Lett 33:1-5. https:// doi.org/10.1029/2005GL024736

Liu WW, Liang J, Donovan EF, Spanswick E (2012) If substorm onset triggers tail reconnection, what triggers substorm onset? J Geophys Res Sp Phys 117:112. https://doi.org/10.1029/2012JA018161

Lopez RE, Lyon JG, Wiltberger MJ, Goodrich CC (2001) Comparison of global MHD simulation results with actual storm and substorm events. Adv Sp Res 28:1701-2001. https://doi.org/10.1016/S0273-1177(01)00535-X

Lotko W, Smith RH, Zhang B, Ouellette JE, Brambles OJ, Lyon JG (2014) Ionospheric control of magnetotail reconnection. Science (80- ) 345:184-187. https://doi.org/10.1126/science.1252907

Lui ATY (1996) Current disruption in the Earth's magnetosphere: observations and models. J Geophys Res Sp Phys 101:13067-13088. https://doi.org/10. 1029/96JA00079

Lui ATY (2011) Reduction of the cross-tail current during near-Earth dipolarization with multisatellite observations. J Geophys Res Sp Phys. https://doi.org/10. 1029/2011JA017107

Lui ATY, Burrows JR (1978) On the location of auroral arcs near substorm onsets. J Geophys Res Sp Phys 83:3342-3348. https://doi.org/10.1029/ JA083iA07p03342

Lui ATY, Mankofsky A, Chang C-L, Papadopoulos K, Wu CS (1990) A current disruption mechanism in the neutral sheet: a possible trigger for substorm 
expansions. Geophys Res Lett 17:745-748. https://doi.org/10.1029/ GL017i006p00745

Lyon JG, Lopez RE, Goodrich CC, Wiltberger M, Papadopoulos K (1998) Simulation of the March 9, 1995, substorm: Auroral brightening and the onset of lobe reconnection. Geophys Res Lett 25:3039-3042. https://doi.org/10.1029/ 98GL00662

Lyons LR, Nishimura Y, Kim H-J, Donovan E, Angelopoulos V, Sofko G, Nicolls M, Heinselman C, Ruohoniemi JM, Nishitani N (2011) Possible connection of polar cap flows to pre- and post-substorm onset PBIs and streamers. J Geophys Res 116:A12225. https://doi.org/10.1029/2011JA016850

Lyons LR, Samson JC (1992) Formation of the stable auroral arc that intensifies at substorm onset. Geophys Res Lett 19:2171-2174. https://doi.org/10.1029/ 92GL02494

Machida S, Miyashita Y, leda A, Nosé M, Nagata D, Liou K, Obara T, Nishida A, Saito Y, Mukai T (2009) Statistical visualization of the Earth's magnetotail based on Geotail data and the implied substorm model. Ann Geophys 27: 1035-1046. https://doi.org/10.5194/angeo-27-1035-2009

McPherron RL (1970) Growth phase of magnetospheric substorms. J Geophys Res 75:5592-5599. https://doi.org/10.1029/JA075i028p05592

McPherron RL (1997) The role of substorms in the generation of magnetic storms. In: Tsurutani BT, Gonzalez DW, Kamide Y, Arballo JK (eds) Magnetic storms. American Geophysical Union, Washington, D. C, pp 131-147

Mcpherron RL, Russell CT, Aubry MP (1973) Satellite studies of magnetospheric substorms on August 15, 1968. IX - phenomenological model for substorms. J Geophys Res 78:3131-3149. https://doi.org/10.1029/JA078i016p03131

Mende SB, Frey HU, Angelopoulos V, Nishimura Y (2011) Substorm triggering by poleward boundary intensification and related equatorward propagation. J Geophys Res Sp Phys 116:A00131. https://doi.org/10.1029/2010JA015733

Meng C-I (1976) Simultaneous observations of low-energy electron precipitation and optical auroral arcs in the evening sector by the DMSP 32 satellite. J Geophys Res 81:2771-2785. https://doi.org/10.1029/JA081i016p02771

Meng C-I, Snyder AL, Kroehl HW (1978) Observations of auroral westward traveling surges and electron precipitations. J Geophys Res 83:575. https:// doi.org/10.1029/JA083iA02p00575

Moriguchi T, Nakamizo A, Tanaka T, Obara T, Shimazu H (2008) Current systems in the Jovian magnetosphere. J Geophys Res 113:A05204. https://doi.org/10. 1029/2007JA012751

Nagai T, Fujimoto M, Saito Y, Machida S, Terasawa T, Nakamura R, Yamamoto T, Mukai T, Nishida A, Kokubun S (1998) Structure and dynamics of magnetic reconnection for substorm onsets with Geotail observations. I Geophys Res Sp Phys 103:4419-4440. https://doi.org/10.1029/97JA02190

Nagai T, Singer HJ, Ledley BG, Olsen RC (1987) Field-aligned currents associated with substorms in the vicinity of synchronous orbit. I - the July 5, 1979, substorm observed by SCATHA, GOES 3, and GOES 2. J Geophys Res 92: 2432-2446. https://doi.org/10.1029/JA092iA03p02432

Nakamura R, Baumjohann W, Klecker B, Bogdanova Y, Balogh A, Reme H, Bosqued J, Dandouras I, Sauvaud J, Glassmeier K, Kistler L, Mouikis C, Zhang $\mathrm{T}$, Eichelberger $\mathrm{H}$, Runov A (2002) Motion of the dipolarization front during a flow burst event observed by Cluster. 29:2-5. doi: https://doi.org/10.1029/ 2002GL015763

Nakamura R, Karlsson T, Hamrin M, Nilsson H, Marghitu O, Amm O, Bunescu C, Constantinescu V, Frey HU, Keiling A, Semeter J, Sorbalo E, Vogt J, Forsyth C, Kubyshkina MV (2014) Low-altitude electron acceleration due to multiple flow bursts in the magnetotail. Geophys Res Lett 41:777-784. https://doi.org/ 10.1002/2013GL058982

Nakayama Y, Ebihara Y, Fok MC, Tanaka T (2017) Impact of substorm time $\mathrm{O}^{+}$outflow on ring current enhancement. J Geophys Res Sp Phys. https://doi. org/10.1002/2016JA023766

Nishida A (1968) Coherence of geomagnetic DP 2 fluctuations with interplanetary magnetic variations. J Geophys Res 73:5549-5559. https://doi. org/10.1029/JA073i017p05549

Nishida A, Fujii K (1976) Thinning of the near-earth (10 15 RE) plasma sheet preceding the substorm expansion phase. Planet Space Sci 24:849-853. https://doi.org/10.1016/0032-0633(76)90075-1

Nishida A, Nagayama N (1973) Synoptic survey for the neutral line in the magnetotail during the substorm expansion phase. J Geophys Res 78:37823798. https://doi.org/10.1029/JA078i019p03782

Nishimura Y, Lyons L, Zou S, Angelopoulos V, Mende S, Sciences O, Angeles L, Physics P, Sciences O, Sciences S, Arbor A (2010) Substorm triggering by new plasma intrusion: THEMIS all-sky imager observations. J Geophys Res 115 A07222. https://doi.org/10.1029/2009JA015166
Nishimura Y, Lyons LR, Kikuchi T, Angelopoulos V, Donovan E, Mende S, Chi PJ, Nagatsuma T (2012) Formation of substorm Pi2: a coherent response to auroral streamers and currents. J Geophys Res 117:A09218. https://doi.org/10. 1029/2012JA017889

Ohtani S-I, Raeder J (2004) Tail current surge: new insights from a global MHD simulation and comparison with satellite observations. J Geophys Res 109: 1207. https://doi.org/10.1029/2002JA009750

Ouellette JE, Brambles OJ, Lyon JG, Lotko W, Rogers BN (2013) Properties of outflow-driven sawtooth substorms. J Geophys Res Sp Phys 118:3223-3232. https://doi.org/10.1002/jgra.50309

Palmroth M, Janhunen P, Germany G, Lummerzheim D, Liou K, Baker DN, Barth C, Weatherwax AT, Watermann J (2006) Precipitation and total power consumption in the ionosphere: global MHD simulation results compared with polar and SNOE observations. Ann Geophys 24:861-872. https://doi.org/ 10.5194/angeo-24-861-2006

Palmroth M, Janhunen P, Pulkkinen TI, Aksnes A, Lu G, Østgaard N, Watermann J, Reeves GD, Germany GA (2005) Assessment of ionospheric Joule heating by GUMICS-4 MHD simulation, AMIE, and satellite-based statistics: towards a synthesis. Ann Geophys 23:2051-2068. https://doi.org/10.5194/angeo23-2051-2005

Papadopoulos K, Goodrich C, Wiltberger M, Lopez R, Lyon JG (1999) The physics of substorms as revealed by the ISTP. Phys Chem Earth, Part C Solar, Terr Planet Sci 24:189-202. https://doi.org/10.1016/S1464-1917(98)00028-2

Parker EN (1957) Newtonian development of the dynamical properties of ionized gases of low density. Phys Rev 107:924-933. https://doi.org/10.1103/PhysRev. 107.924

Perreault P, Akasofu S-I (1978) A study of geomagnetic storms. Geophys J Int 54: 547-573. https://doi.org/10.1111/j.1365-246X.1978.tb05494.x

Pritchett PL, Coroniti FV, Nishimura Y (2014) The kinetic ballooning/interchange instability as a source of dipolarization fronts and auroral streamers. J Geophys Res Sp Phys 119:4723-4739. https://doi.org/10.1002/2014JA019890

Pulkkinen TI, Baker DN, Pellinen RJ, Büchner J, Koskinen HEJ, Lopez RE, Dyson RL, Frank LA (1992) Particle scattering and current sheet stability in the geomagnetic tail during the substorm growth phase. J Geophys Res 97: 19283. https://doi.org/10.1029/92JA01189

Pulkkinen TI, Baker DN, Wiltberger M, Goodrich C, Lopez RE, Lyon JG (1998) Pseudobreakup and substorm onset: observations and MHD simulations compared. J Geophys Res Sp Phys 103:14847-14854. https://doi.org/10.1029/ 97JA03244

Rae IJ, Watt CEJ, Mann IR, Murphy KR, Samson JC, Kabin K, Angelopoulos V (2010) Optical characterization of the growth and spatial structure of a substorm onset arc. J Geophys Res Sp Phys 115:1-10. https://doi.org/10.1029/ 2010JA015376

Raeder J, McPherron RL, Frank LA, Kokubun S, Lu G, Mukai T, Paterson WR, Sigwarth JB, Singer HJ, Slavin JA (2001) Global simulation of the Geospace environment modeling substorm challenge event. J Geophys Res Sp Phys 106:381-395. https://doi.org/10.1029/2000JA000605

Raeder J, Zhu P, Ge Y, Siscoe G (2010) Open geospace general circulation model simulation of a substorm: axial tail instability and ballooning mode preceding substorm onset. J Geophys Res Sp Phys 115:n/a-n/a. doi: https:// doi.org/10.1029/2010JA015876

Raeder J, Zhu P, Ge Y, Siscoe G (2012) Auroral signatures of ballooning mode near substorm onset: open geospace general circulation model simulations. In: Keiling A, Donovan EF, Bagenal F, Karlsson T (eds) Auroral phenomenology and Magnetospheric processes: \{earth\} and other planets. American Geophysical Union, Washington, D. C, pp 389-395

Rème H, Bosqued JM (1973) Rocket observations of electron precipitation in a westward-traveling surge. J Geophys Res 78:5553-5558. https://doi.org/10. 1029/JA078i025p05553

Richmond AD, Kamide Y, Akasofu S-I, Alcaydé D, Blanc M, de la Beaujardière $\mathrm{O}$, Evans DS, Foster JC, Friis-Christensen E, Holt JM, Pellinen RJ, Senior C, Zaitzev AN (1990) Global measures of ionospheric electrodynamic activity inferred from combined incoherent scatter radar and ground magnetometer observations. J Geophys Res 95:1061. https://doi.org/10.1029/ JA095iA02p01061

Roelof EC, Brandt PC, Mitchell DG (2004) Derivation of currents and diamagnetic effects from global plasma pressure distributions obtained by IMAGE/HENA. Adv Sp Res 33:747-751. https://doi.org/10.1016/S0273-1177(03)00638-0

Rothwell PL, Silevitch MB, Block LP (1984) A model for the propagation of the westward traveling surge. J Geophys Res 89:8941. https://doi.org/10.1029/ JA089iA10p08941 
Roux A, Perraut S, Robert P, Morane A, Pedersen A, Korth A, Kremser G, Aparicio B, Rodgers D, Pellinen R (1991) Plasma sheet instability related to the westward traveling surge. J Geophys Res 96:17697. https://doi.org/10.1029/ 91JA01106

Saita S, Kadokura A, Sato N, Fujita S, Tanaka T, Ebihara Y, Ohtani S, Ueno G, Murata K, Matsuoka D, Kitamoto A, Higuchi T (2011) Displacement of conjugate points during a substorm in a global magnetohydrodynamic simulation. J Geophys Res Phys 116: doi: https://doi.org/10.1029/ 2010ja016155

Sergeev V, Angelopoulos V, Kubyshkina M, Donovan E, Zhou XZ, Runov A, Singer H, McFadden J, Nakamura R (2011) Substorm growth and expansion onset as observed with ideal ground-spacecraft THEMIS coverage. J Geophys Res Sp Phys 116:A00I26. https://doi.org/10.1029/2010JA015689

Sergeev VA, Sauvaud J-A, Popescu D, Kovrazhkin RA, Liou K, Newell PT, Brittnacher M, Parks G, Nakamura R, Mukai T, Reeves GD (2000) Multiplespacecraft observation of a narrow transient plasma jet in the Earth's plasma sheet. Geophys Res Lett 27:851-854. https://doi.org/10.1029/1999GL010729

Shi QQ, Zong Q-G, Fu SY, Dunlop MW, Pu ZY, Parks GK, Wei Y, Li WH, Zhang H, Nowada M, Wang YB, Sun WJ, Xiao T, Reme H, Carr C, Fazakerley a N, Lucek E (2013) Solar wind entry into the high-latitude terrestrial magnetosphere during geomagnetically quiet times. Nat Commun 4:1466. https://doi.org/10. 1038/ncomms2476

Shiokawa K, Baumjohann W, Haerendel G (1997) Braking of high-speed flows in the near-Earth tail. Geophys Res Lett 24:1179. https://doi.org/10.1029/97GL01062

Silsbee HC, Vestine EH (1942) Geomagnetic bays, their frequency and current systems. J Geophys Res 47:195. https://doi.org/10.1029/TE047i003p00195

Siscoe GL, Crooker NU, Erickson GM, Sonnerup BU, Ouml SKD, Weimer DR, White WW, Maynard NC (2000) Global geometry of magnetospheric currents inferred from MHD simulations. Magnetos Curr Syst 118:41-52. https://doi. org/10.1029/GM118p0041

Siscoe GL, Cummings WD (1969) On the cause of geomagnetic bays. Planet Space Sci 17:1795-1802. https://doi.org/10.1016/0032-0633(69)90055-5

Slinker SP, Fedder JA, Ruohoniemi JM, Lyon JG (2001) Global MHD simulation of the magnetosphere for November 24, 1996. J Geophys Res Sp Phys 106:361380. https://doi.org/10.1029/2000JA000603

Song Y, Lysak RL (2001a) The physics in the auroral dynamo regions and auroral particle acceleration. Phys Chem Earth, Part C Solar, Terr Planet Sci 26:33-42. https://doi.org/10.1016/S1464-1917(00)00087-8

Song Y, Lysak RL (2001b) Towards a new paradigm: from a quasi-steady description to a dynamical description of the magnetosphere. Space Sci Rev 95:273-292. https://doi.org/10.1023/A:1005288420253

Stepanova MV, Antonova EE, Bosqued JM, Kovrazhkin RA, Aubel KR (2002) Asymmetry of auroral electron precipitations and its relationship to the substorm expansion phase onset. J Geophys Res Sp Phys. https://doi.org/10. 1029/2001JA003503

Sun W, Ahn BH, Akasofu SI (1985) The global joule heat production rate and the AE index. Planet Space Sci 33:279-281. https://doi.org/10.1016/00320633(85)90059-5

Takahashi K, Zanetti LJ, Lopez RE, McEntire RW, Potemra TA, Yumoto K (1987) Disruption of the magnetotail current sheet observed by AMPTE/CCE. Geophys Res Lett 14:1019-1022. https://doi.org/10.1029/GL014i010p01019

Tanaka T (1994) Finite volume TVD scheme on an unstructured grid system for three-dimensional MHD simulation of inhomogeneous systems including strong background Potential fields. J Comput Phys 111:381-389

Tanaka T (1995) Generation mechanisms for magnetosphere-ionosphere current systems deduced from a three-dimensional MHD simulation of the solar wind-magnetosphere-ionosphere coupling processes. J Geophys Res 100: 12057-12074. https://doi.org/10.1029/95JA00419

Tanaka T (2000a) Field-aligned-current systems in the numerically simulated magnetosphere. Magnetos Curr Syst Geophys Monogr Ser 118:53-59

Tanaka T (2000b) The state transition model of the substorm onset. J Geophys Res Sp Phys 105:21081-21096. https://doi.org/10.1029/2000JA900061

Tanaka T (2015) Substorm auroral dynamics reproduced by advanced global magnetosphere-ionosphere (M-I) coupling simulation. In: Auroral dynamics and space weather. Wiley, Hoboken, pp 177-190

Tanaka T, Ebihara Y, Watanabe M, Den M, Fujita S, Kikuchi T, Hashimoto KK, Kataoka R (2017a) Global simulation study for the time sequence of events leading to the subsorm onset. J Geophys Res Sp Phys:6210-6239. https://doi. org/10.1002/2017JA024102

Tanaka T, Nakamizo A, Yoshikawa A, Fujita S, Shinagawa H, Shimazu H, Kikuchi T, Hashimoto KK (2010) Substorm convection and current system deduced from the global simulation. J Geophys Res Sp Phys 115:A05220. https://doi. org/10.1029/2009JA014676

Tanaka T, Obara T, Watanabe M, Fujita S, Ebihara Y, Kataoka R (2017b) Formation of the Sun-aligned arc region and the void (polar slot) under the nullseparator structure. J Geophys Res Sp Phys 122:4102-4116. https://doi.org/10. 1002/2016JA023584

Tanaka T, Watanabe M, Den M, Fujita S, Ebihara Y, Kikuchi T, Hashimoto KK, Kataoka R (2016) Generation of field-aligned current (FAC) and convection through the formation of pressure regimes: correction for the concept of Dungey's convection. J Geophys Res A Sp Phys. https://doi.org/10.1002/ 2016JA022822

Tanskanen E, Pulkkinen TI, Koskinen HEJ, Slavin JA (2002) Substorm energy budget during low and high solar activity: 1997 and 1999 compared. J Geophys Res 107:1086. https://doi.org/10.1029/2001JA900153

Treumann RA, Jaroschek CH, Nakamura R, Runov A, Scholer M (2006) The role of the Hall effect in collisionless magnetic reconnection. Adv Sp Res 38:101111. https://doi.org/10.1016/j.asr.2004.11.045

Weimer DR, Craven JD, Frank LA, Hanson WB, Maynard NC, Hoffman RA, Slavin JA (1994) Satellite measurements through the center of a substorm surge. J Geophys Res 99:23639. https://doi.org/10.1029/94JA01976

Welling DT, Jordanova VK, Zaharia SG, Glocer A, Toth G (2011) The effects of dynamic ionospheric outflow on the ring current. J Geophys Res Sp Phys 116:n/a-n/a. doi: https://doi.org/10.1029/2010JA015642

Wiltberger M, Pulkkinen TI, Lyon JG, Goodrich CC (2000a) MHD simulation of the magnetotail during the December 10, 1996, substorm. J Geophys Res 105: 27649. https://doi.org/10.1029/1999JA000251

Yahnin AG, Sergeev VA, Gvozdevsky BB, Vennerstrøm S (1997) Magnetospheric source region of discrete auroras inferred from their relationship with isotropy boundaries of energetic particles. Ann Geophys 15:943-958. https:// doi.org/10.1007/s00585-997-0943-z

Yao Y, Ebihara Y, Tanaka T (2015a) Formation and evolution of high-plasmapressure region in the near-Earth plasma sheet: precursor and postcursor of substorm expansion onset. J Geophys Res Sp Phys 120:6427-6435. https:// doi.org/10.1002/2015JA021187

Yao Y, Ebihara Y, Tanaka T (2015b) Sudden pressure enhancement and tailward retreat in the near-Earth plasma sheet: THEMIS observation and MHD simulation. J Geophys Res Sp Phys 120:201-211. https://doi.org/10.1002/ 2014JA020482

Zhang Y, Paxton LJ, Newell PT, Meng Cl (2009) Does the polar cap disappear under an extended strong northward IMF? J Atmos Solar-Terrestrial Phys 71: 2006-2012. https://doi.org/10.1016/j.jastp.2009.09.005

\section{Submit your manuscript to a SpringerOpen ${ }^{\circ}$ journal and benefit from:}

- Convenient online submission

- Rigorous peer review

- Open access: articles freely available online

High visibility within the field

- Retaining the copyright to your article

Submit your next manuscript at $>$ springeropen.com 